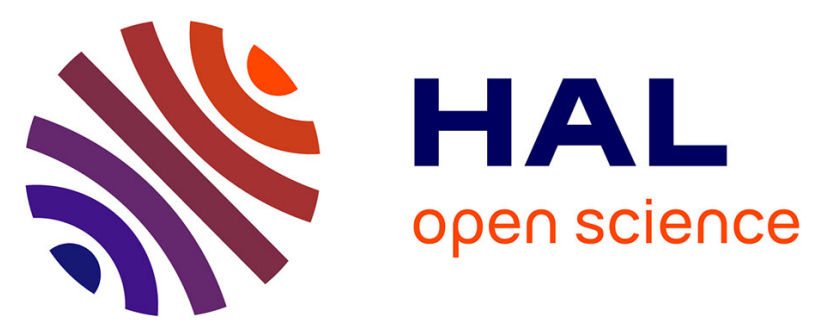

\title{
Cyclam-Based Chelators Bearing Phosphonated Pyridine Pendants for 64 Cu-PET Imaging: Synthesis, Physicochemical Studies, Radiolabeling, and Bioimaging
}

Richard C Knighton, Thibault Troadec, Valérie Mazan, Patricia Le Saëc, Séverine Marionneau-Lambot, Thomas Le Bihan, Nathalie Saffon-merceron, Nathalie Le Bris, Michel Chérel, Alain Faivre-Chauvet, et al.

\section{To cite this version:}

Richard C Knighton, Thibault Troadec, Valérie Mazan, Patricia Le Saëc, Séverine MarionneauLambot, et al.. Cyclam-Based Chelators Bearing Phosphonated Pyridine Pendants for $64 \mathrm{Cu}-\mathrm{PET}$ Imaging: Synthesis, Physicochemical Studies, Radiolabeling, and Bioimaging. Inorganic Chemistry, 2021, 60 (4), pp.2634-2648. 10.1021/acs.inorgchem.0c03492 . hal-03123032

\author{
HAL Id: hal-03123032 \\ https://hal.science/hal-03123032
}

Submitted on 17 May 2021

HAL is a multi-disciplinary open access archive for the deposit and dissemination of scientific research documents, whether they are published or not. The documents may come from teaching and research institutions in France or abroad, or from public or private research centers.
L'archive ouverte pluridisciplinaire HAL, est destinée au dépôt et à la diffusion de documents scientifiques de niveau recherche, publiés ou non, émanant des établissements d'enseignement et de recherche français ou étrangers, des laboratoires publics ou privés. 


\title{
Cyclam-based Chelators Bearing Phosphonated Pyridine Pendants for ${ }^{64} \mathrm{Cu}$-PET Imaging: Synthesis, Physico-chemical Studies, Radiolabeling and Bioimaging
}

Richard C. Knighton, ${ }^{a}$ Thibault Troadec, ${ }^{* a}$ Valérie Mazan, ${ }^{c}$ Patricia Le Saëc, ${ }^{\text {b }}$ Séverine Marionneau-Lambot, ${ }^{\text {b }}$ Thomas Le Bihan, ${ }^{a}$ Nathalie Saffon-Merceron, ${ }^{d}$ Nathalie Le Bris, ${ }^{a}$ Michel Chérel, ${ }^{b}$ Alain Faivre-Chauvet, ${ }^{b}$ Mourad Elhabiri, ${ }^{c}$ Loïc J. Charbonnière, ${ }^{\mathrm{e}}$ Raphaël Tripier*a

\footnotetext{
a UMR 6521, Université de Bretagne Occidentale, 6 Avenue Victor Le Gorgeu, Brest, France; E-mail: thibault.troadec@univbrest.fr; raphael.tripier@univ-brest.fr

b Université de Nantes, Centre de Recherche en Cancérologie et Immunologie Nantes Angers (CRCINA), Unité INSERM 1232 CNRS 6299, 8 quai Moncousu, BP 70721, 44007 Nantes Cedex, France.

${ }^{\mathrm{C}}$ ECPM, UMR 7509, 25 rue Becquerel, 67087 Strasbourg Cedex 2, France.

${ }^{\mathrm{d}}$ Institut de Chimie de Toulouse (FR 2599), 118 route de Narbonne, 31062 Toulouse Cedex 9, France.

e UMR 7178, Insitut Pluridisciplinaire Hubert Curien, Université de Strasbourg, , ECPM, 25 rue Becquerel, 67087 Strasbourg Cedex 2, France.
}

\begin{abstract}
Herein we present the preparation of two novel cyclam-based macrocycles (te1pyp and cb-te1pyp), bearing phosphonate-appended pyridine side-arms, that combine the properties of previously described methylphosphonate and picolinate coordinating units for the coordination of copper(II) ions in the context of ${ }^{64} \mathrm{CU}$ PET imaging. The two ligands have been prepared through conventional protection-alkylation sequences on cyclam, and their coordination properties have been thoroughly investigated. The corresponding copper complexes have been fully characterized in the solid-state (X-Ray diffraction analysis) and in solution (EPR and UV-Vis spectroscopies). Potentiometric studies, combined with spectrometry, have also allowed us to determine their thermodynamic stability constants to confirm their high affinity for copper(II) cations. The kinetic inertness of the complexes has also been demonstrated by acidassisted dissociation experiments, enabling their first use for ${ }^{64} \mathrm{Cu}$-PET imaging in mice. Indeed, the two ligands could be quantitatively radiolabelled in mild conditions, and the resulting ${ }^{64} \mathrm{Cu}$ complexes have demonstrated excellent stability in serum. PET imaging demonstrated the set of features emerging from the combination of picolinates and phosphonate units : high stability in vivo, a fast clearance from the body via renal elimination, and most interestingly very low fixation in the liver. The latter is in contrast with what was observed for monopicolinate cyclam (te1pa), that had a non-neglictible accumulation in that organ, owing probably to its different charge and lipophillicity. These results are thus paving the way for the use of such phosphonated pyridine chelators for in vivo ${ }^{64} \mathrm{CU}$-PET applications.
\end{abstract}




\section{Introduction}

Positron Emission Tomography (PET) has emerged in the last decades as a key medical imaging modality, in the detection of physiological disorders and pathologies, and particularly in cancer detection. This technique relies on the injection of a radiopharmaceutical tracer, i.e. a molecule bearing a targeting moiety and labelled by a positron $\left(\beta^{+}\right)$emitting radionuclide. The main benefits of PET, over other techniques, are its non-invasive character and very high sensitivity (nM concentration). In the clinic, the dominating tracer is ${ }^{18} \mathrm{~F}$-Fluorodeoxyglucose $\left({ }^{18} \mathrm{~F}-\mathrm{FDG}\right)$, a glucose molecule labelled with $\beta^{+}$-emitting ${ }^{18} \mathrm{~F}$, that relies on the Warburg effect in cancer cells, i.e. fast and high uptake of glucose to sustain their altered energy production mechanisms. ${ }^{1}$ Although this tracer has a wide scope, it lacks specificity for the detection of some tumours, for instance in highly glucose-consuming organs such as the brain and liver. ${ }^{2}$ In addition, ${ }^{18} \mathrm{~F}$ has a short half-life $\left(t_{1 / 2}=110 \mathrm{~min}\right)$ that matches the fast glucose distribution in vivo, but is not appropriate for slower physiological mechanisms and labelling of biomolecules with longer biodistribution times (antibodies, peptides). Thus, there is a high demand for new radiopharmaceuticals based on radionuclides having longer half-lives. In this context, ${ }^{64} \mathrm{Cu}\left(\mathrm{t}_{1 / 2}=12.7 \mathrm{~h}\right)$ is a nucleus of choice, and there is a strong need for chelating ligands that can accommodate copper(II) ions. To envisage an easy preparation of radiotracers and a safe use as PET tracers in vivo, a common set of characteristics is considered in the design of suitable ligands : i) high thermodynamic stability of the copper(II) complex (assessed by thermodynamic constants); ii) kinetic inertness, i.e. robustness towards transchelation and transmetallation (measured in vivo or by dissociation experiments in competitive media); iii) soft radiolabelling conditions to preserve the integrity of sensitive targeting units (antibodies in particular); ${ }^{3}$ iv) good clearance from the body and the absence of undesired organ accumulation, which can have deleterious toxicological effects. To fulfil these attributes, nitrogen-based chelators have demonstrated their superior capabilities, and a large effort has been devoted in the last two decades to the design of functionalized polyazamacrocycles, ${ }^{4}$ from cyclen and cyclam scaffolds in particular. Acetate coordinating pendant arms have long been used to increase the number of donor atoms and complex stability, and their characteristics are now well-known. More recently, phosphonate pendants have been introduced, and precise combinations of macrocyclic platform and side-arms have allowed a fine control of the chelators properties, following a few clear trends.

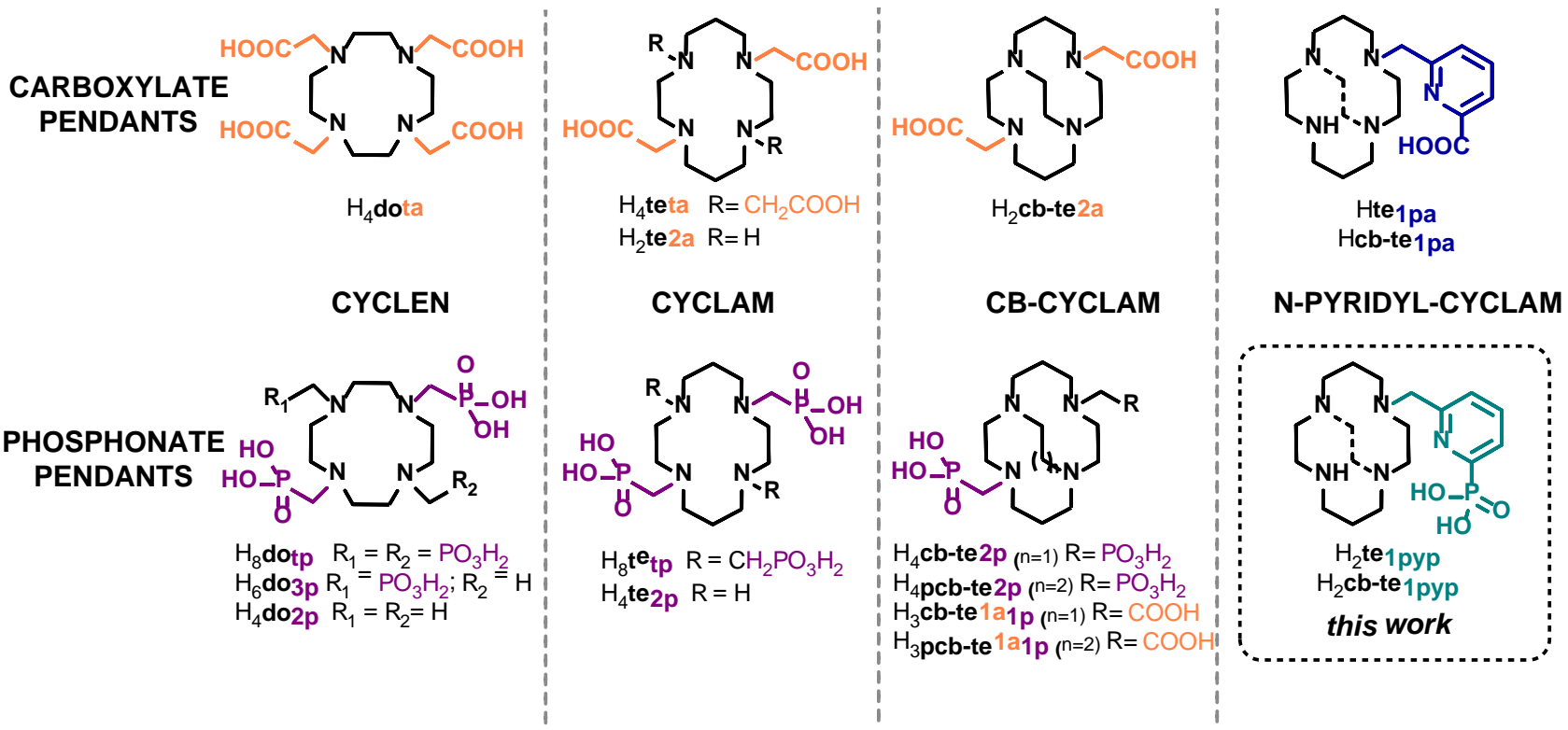

Figure 1 : Copper(II) chelators discussed in this paper 
Owing to its commercial availability and coordination properties towards a wide range of metallic cations, dota, (cyclen bearing four acetic acid coordinating side-arms, Figure 1) has been extensively studied and its analogues are still used in preclinical investigations for copper complexation and PET applications. ${ }^{5}$ However, its lack of selectivity for copper and the metal dissociation occurring in competitive media are detrimental for human in vivo use. ${ }^{6}$ When moving to larger cyclam-based teta congener, a strong increase in copper selectivity is observed. Indeed, teta exhibits a stability constant with copper similar to dota ( $\log \mathrm{K}_{\mathrm{Cul}}=21.1$ and 22.2 respectively), but a marked preference for copper(II) over zinc(II) (log $\mathrm{K}_{\mathrm{znL}}=17.5$ and 21.1 respectively), ${ }^{7}$ a competitive biologically-abundant cation. However, the kinetic inertness of the complexes is still below requirements. ${ }^{8}$ Nevertheless, studies on te2a, bearing only two acetate units, have clearly demonstrated that reducing the number of coordinating pendants to match copper(II) preferred coordinating numbers (5-6) drastically improves the kinetic inertness of the corresponding copper complexes $\left(t_{1 / 2}=\right.$ $92 \mathrm{~h}$ for te2a vs. $4 \mathrm{~h}$ for teta in $5 \mathrm{M} \mathrm{HCl}$ at $\left.50{ }^{\circ} \mathrm{C}\right) .{ }^{9}$ The cross-bridged analogue cb-te2a, exhibiting an extra ethylene linkage between two trans- nitrogen atoms, also demonstrates high inertness attributed to the rigidity of its preorganized cavity. ${ }^{10}$ However, complexation kinetics are dramatically reduced with such architectures, and harsh conditions are necessary for quantitative radiolabelling with ${ }^{64} \mathrm{Cu}\left(\mathrm{T}>75^{\circ} \mathrm{C}\right.$ and $\mathrm{t}>1 \mathrm{~h}$ for cb-te2a $\mathrm{a}^{11,12}$ vs. 5 min at $30^{\circ} \mathrm{C}$ for te2a). ${ }^{9}$ In this context, some of us have recently prepared picolinate-functionalized cyclam and cross-bridged cyclam te1pa and cb-te1pa, presenting an ideal combination of thermodynamic stability, copper selectivity, inertness and fast complexation kinetics. ${ }^{13-15}$ To access in vivo applications while retaining te1pa coordination properties, the cyclam scaffold could be derivatized to design a bifunctional analogue, which was successfully grafted on antibodies for immuno-PET imaging on mice. ${ }^{16-18}$

In addition to this scaffold tuning, methylphosphonate side-arms have also attracted attention and facilitate modulation of the ligand coordination properties. As a general trend, compared to carboxylates, they have been shown to provide faster copper(II) complexation kinetics, but at the detriment of inertness. These features were exemplified on cyclen derivatives with a systematic series of dota analogues where up to four acetate pendants were replaced by methylphosphonates. ${ }^{19}$ The same behaviour is observed on cyclam scaffolds, with teta and te2a showing much higher inertness $\left(4\right.$ and $92 \mathrm{~h}$ in $5 \mathrm{M} \mathrm{HCl}$ at $50^{\circ} \mathrm{C}$ respectively) ${ }^{9}$ than their phosphonated counterparts tetp and te2p (19 min in $1 \mathrm{M} \mathrm{HClO}_{4}$ at $25^{\circ} \mathrm{C}$ for te2p). ${ }^{20,21}$ Finally, as previously demonstrated for the carboxylate parents, addition of an ethylene- or propylene-cross-bridged in cb-te2p and pcb-te2p leads to more inert complexes, ${ }^{10,22}$ even if lower in magnitude than the corresponding cb-te2a and pcb-te2a. ${ }^{10,23}$ However, faster complexation kinetics and radiolabelling are still observed for the phosphonated macrocycles.

Finally, the nature and charge of the side-arms strongly affects the biodistribution of the injected complexes. Although both series generally show fast blood clearance due to the small size of the complexes, phosphonateappended complexes show a usual renal elimination, whereas hepatic accumulation can be observed with the carboxylate congeners. This is in some cases due to free copper resulting from complex dissociation, as demonstrated for dota and teta, ${ }^{15,24}$ or simply to a hepatic affinity of the molecule in the case of perfectly inert complexes. ${ }^{17}$ The capacity of phosphonates to reduce this behaviour was clearly demonstrated with phosphonate and mixed acetate/methylphosphonate ligands $(\mathbf{p}) \mathbf{c b}$-te2p and $(\mathbf{p}) \mathbf{c b}$-te1a1p when compared to the cb-te2a analogue. ${ }^{10,23,25-27}$ 
However, increasing the number of phosphonate groups to three or four is detrimental with accumulation increasing in both the liver and kidneys. ${ }^{28}$

Based on these trends, we sought to develop te1pyp and cb-te1pyp, cyclam and cross-bridged cyclam macrocycles mono-functionnalized with a 2-phosphorylpyridyl side-arm, a coordinating unit that has been recently used by our groups for lanthanide coordination. ${ }^{29-31}$. The two novel ligands are expected to combine the stability and inertness of our successful te1pa and cb-te1pa complexes with reduced hepatic accumulation owing to the replacement of the carboxylate by a phosphonate moiety. Herein, we present a thorough description of the synthesis, solution and solid-state studies, physico-chemical properties, radiolabelling and PET imaging ability of these two novel copper(II) chelators.

\section{Results and Discussion}

Synthesis of ligands, complexes and solid-state structures. The synthetic protocol for the preparation of the ligands is depicted in Scheme 1 and full experimental details can be found in the experimental section (Section 2).

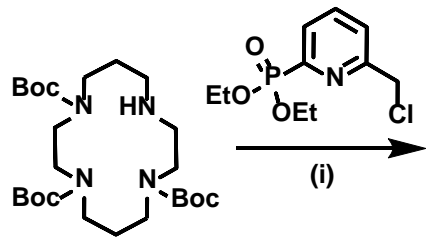

(Boc) ${ }_{3}$ cyclam

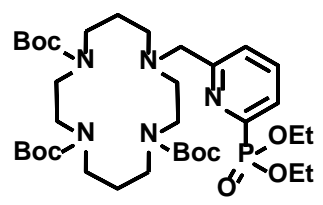

1

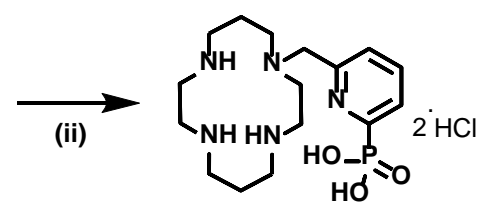

$\mathrm{H}_{2}$ te1pyp $2 \mathrm{HCl}$

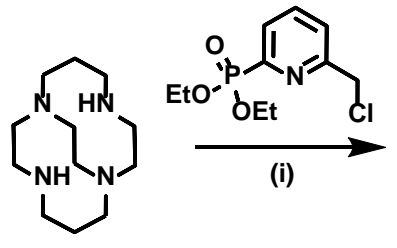

cb-cyclam

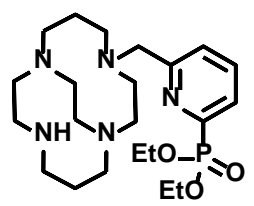

2

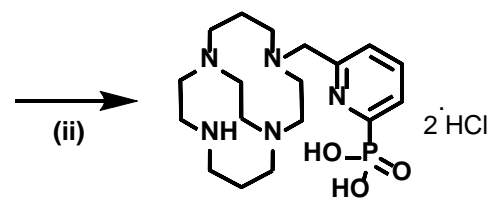

$\mathrm{H}_{2}$ cb-te1pyp $2 \mathrm{HCl}$

Scheme 1: Synthetic protocol for the preparation of the ligands; $\mathrm{H}_{2}$ te1pyp and $\mathrm{H}_{2}$ cb-te1pyp; (i) $\mathrm{K}_{2} \mathrm{CO}_{3}, \mathrm{MeCN}, \mathrm{RT}, 36$ hr (1 58\%; 2. HCl 84\%) (ii) $6 \mathrm{M} \mathrm{HCl}_{(\text {(aq) }}, 100^{\circ} \mathrm{C}, 36$ hr ( $\mathrm{H}_{2}$ te1pyp 89\%; $\mathrm{H}_{2}$ cb-te1pyp 60\%)

The target monofunctionalised cyclam ligands $\mathrm{H}_{2}$ te1pyp and $\mathrm{H}_{2}$ cb-te1pyp were synthesised according to an operationally simple procedure. The tris(tert-butoxycarbonyl)-protected cyclam precursor ${ }^{32}$ was alkylated with diethyl (6-(chloromethyl)pyridin-2-yl)phosphonate ${ }^{29}$ in anhydrous acetonitrile under basic conditions to obtain the triprotected intermediate 1 in 58\% yield. The ligand $\mathrm{H}_{2}$ te1pyp was obtained via simultaneous cleavage of the acid sensitive Boc and ester protecting groups using aqueous $\mathrm{HCl}$ yielding $89 \%$ of isolated compound after recrystallization. The corresponding cross-bridged intermediate $\mathbf{2}$ was obtained in $84 \%$ yield following a controlled statistical alkylation. Again, deprotection and recrystallization furnished the target $\mathrm{H}_{2} \mathrm{cb}$-te1pyp in good yield (60\%).

The novel ligands $\mathrm{H}_{2}$ te1pyp and $\mathrm{H}_{2}$ cb-te1pyp were investigated for the ability to chelate $\mathrm{Cu}^{2+}$ ions. Complexation of the metal as the perchlorate salt was achieved in $\mathrm{H}_{2} \mathrm{O}(\mathrm{pH}=6.5-7.0)$, obtaining the paramagnetic complexes [Cu(te1pyp) $\mathrm{H}]\left[\mathrm{ClO}_{4}\right](88 \%)$ and $[\mathrm{Cu}(\mathrm{cb}-\mathrm{te} 1 \mathrm{pyp}) \mathrm{H}]\left[\mathrm{ClO}_{4}\right](38 \%)$ after acidification $(\mathrm{pH}=3.5-4.0)$ and purification by $\mathrm{C}_{18}$ chromatography. Complexes gave characteristic ESI-HRMS peaks and their purity was confirmed by analytical HPLCMS (See ESI, Section 2.2.2). The diamagnetic zinc(II) congeners were prepared via an analogous procedure 
([Zn(te1pyp)H][ClO 4$], 57 \%$; $\mathrm{Zn}(\mathrm{cb}$-te1pyp) $\mathrm{H}]\left[\mathrm{ClO}_{4}\right], 60 \%$ ), and were fully characterised by ${ }^{1} \mathrm{H},{ }^{13} \mathrm{C},{ }^{31} \mathrm{P}$ NMR and ESIHRMS (See ESI, Section 2.2.1).

Figure $\mathbf{X}$ : Single crystal X-rays structures of; (left) [Cu(te1pyp)H $]^{+}$, (right) [Cu(cb-te1pyp)H] $]^{+}$(Ellipsoids are plotted at $30 \%$ and $50 \%$ respectively, non-heteroatoms hydrogen bonds, solvents and anions are omitted for clarity; $\mathrm{Cnt}=$ macrocycle centroid).

Slow evaporation of concentrated $\mathrm{H}_{2} \mathrm{O}$ solutions of the copper complexes yielded crystals suitable for analysis by single crystal X-ray diffraction (See ESI, Section 3 for full details). Both complexes crystallise in the monoclinic P2/1 $1_{\mathrm{c}}$ space group, and reveal the extended Cu1-01/3 distances and thus 5-coordinate $\left(\mathrm{N}_{5}\right)$ complexes (Table 1). Comparing the native and cross-bridged variant, [Cu(te1pyp) $]^{+}$shows shortened cyclam metal-nitrogen distances and a lengthened metal-pyridine bond (largest $\Delta \AA=0.361 \AA$ ), whereas [ $\mathrm{Cu}(\mathrm{cb} \text {-te1pyp) }]^{+}$exhibits broadly similar $\mathrm{Cu}-\mathrm{N}$ bond lengths (largest $\Delta \AA=0.147 \AA$ ). This disparity is reflected in the coordination sphere of each complex; the calculated values are $\tau=0.43$ and $\tau=0.62$ for $[\mathrm{Cu}(\text { te1pyp }) \mathrm{H}]^{+}$and $\left[\mathrm{Cu}(\mathrm{cb}-\text { te1pyp) }]^{+}\right.$respectively, indicating a tendency away from the square pyramidal geometry of $[\mathrm{Cu}(\mathrm{te} 1 \mathrm{pyp}) \mathrm{H}]^{+}$towards a trigonal bipyramidal geometry in $[\mathrm{Cu}(\mathrm{cb}-\mathrm{te} 1 \mathrm{pyp}) \mathrm{H}]^{+}{ }^{33} \mathrm{The}$ difference in metal coordination geometry is mirrored in the lateral displacement of the copper ion away from the

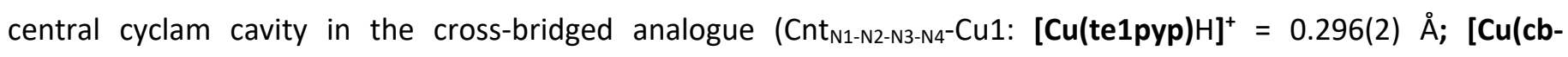
te1pyp) $\mathrm{H}^{+}=0.771(1) \AA$ ). Despite the absence of phosphonate oxygen coordination, both structures reveal supplementary stabilising hydrogen bonding between the phosphonate oxygen atoms and the azamacrocyclic $\mathrm{NH}$ atoms $\left(\left[\mathrm{Cu}(\text { te1pyp)H }]^{+}: \mathrm{N} 3-\mathrm{O} 1=3.131(6) \AA, \mathrm{N} 3-\mathrm{O} 3=3.125(6) \AA\right.\right.$; $[\mathrm{Cu}(\mathrm{cb}-\mathrm{te} 1 \mathrm{pyp}) \mathrm{H}]^{+}: \mathrm{N} 3-\mathrm{O} 1=2.867(2) \AA$, N3-O3 = $3.470(2) \AA ̊$ ), which encloses the central copper ion and increases the stability/inertness of the complexes (vide infra), as in the case of previously described picolinate moiety. ${ }^{13}$

\begin{tabular}{ccccccccc}
\hline & Cu1-N1 & Cu1-N2 & Cu1-N3 & Cu1-N4 & Cu1-N5 & N3-01 & N3-03 & $\tau$ \\
\hline$[$ Cu(te1pyp) $]$ & $2.035(4)$ & $2.038(5)$ & $1.984(5)$ & $2.054(5)$ & $2.345(4)$ & $3.131(6)$ & $3.125(6)$ & 0.427 \\
${\text { [Cu(CB-te1pypH) }]^{+}}^{2} 2.143(2)$ & $2.082(2)$ & $1.996(2)$ & $2.006(2)$ & $2.077(2)$ & $2.867(2)$ & $3.470(2)$ & 0.619 \\
\hline
\end{tabular}

Table 1: Selected bond lengths for novel $\mathrm{Cu}^{\text {II }}$ complexes $(\AA)$ 
Solution-state properties - Zn(II) complexes. The paramagnetic character of the copper(II) complexes precludes their characterisation using NMR analysis. Consequently, the diamagnetic zinc(II) complexes were employed as a surrogate for elucidation of the solution-state structural properties of the novel complexes. NMR spectra were recorded -in an analogous fashion to the ligands - in aqueous solutions $\left(D_{2} \mathrm{O}, \mathrm{pD} \approx 7.0,400 \mathrm{MHz}, 298 \mathrm{~K}\right)$. At this $\mathrm{pD}$, by analogy with their corresponding $\mathrm{Cu}^{2+}$ counterparts (vide infra), these complexes are neutral in solution, both phosphonate oxygen atoms being deprotonated and compensating the $\mathrm{Zn}^{2+}$ charge. As a general comparison both [Zn(te1pyp)] and its cross-bridged congener [Zn(cb-te1pyp)] exhibit significant perturbations of the ${ }^{1} \mathrm{H}$ NMR spectra compared to their respective free ligands upon complexation of the electropositive zinc(II) metal cation, notably for the diastereotopic methylene $\mathrm{CH}_{2}$ protons corresponding to the 2-phosphorylpyridine arm. The solution-state analysis by ${ }^{1} \mathrm{H}$ NMR also shows that the cross-bridged [Zn(cb-te1pyp)] complex exhibits time-averaged $C_{1}$ symmetry in solution - mirroring the solid-state copper geometry - consistent with fast interconversion on the ${ }^{1} \mathrm{H}$ NMR timescale. The symmetry is typified by diastereotopic resonances $(\delta=4.63$ and $3.74 \mathrm{ppm}$ ) of the methylenic 6-phosphonated pyridine moiety. Other salient features include the observation of a slowly exchanging $\mathrm{N} \underline{\mathrm{H}}$ resonance- tentatively assigned to the proton $\mathrm{H}$ bonding to the pendant phosphonate group (vide supra; Figure $\mathbf{X}$ ). The corresponding [Zn(te1pyp)] complex again presents a pseudo- $C_{1}$ symmetry but exhibits more dynamic behaviour with several methylenic resonances approaching the fast-exchange limit ( $400 \mathrm{MHz}, 298 \mathrm{~K}$ ). This can be rationalised by the less rigid structure of the unfunctionalised complex in comparison to the rigid geometry imposed by the cross-bridged appendage, which reduce degrees of freedom of the cyclam backbone.

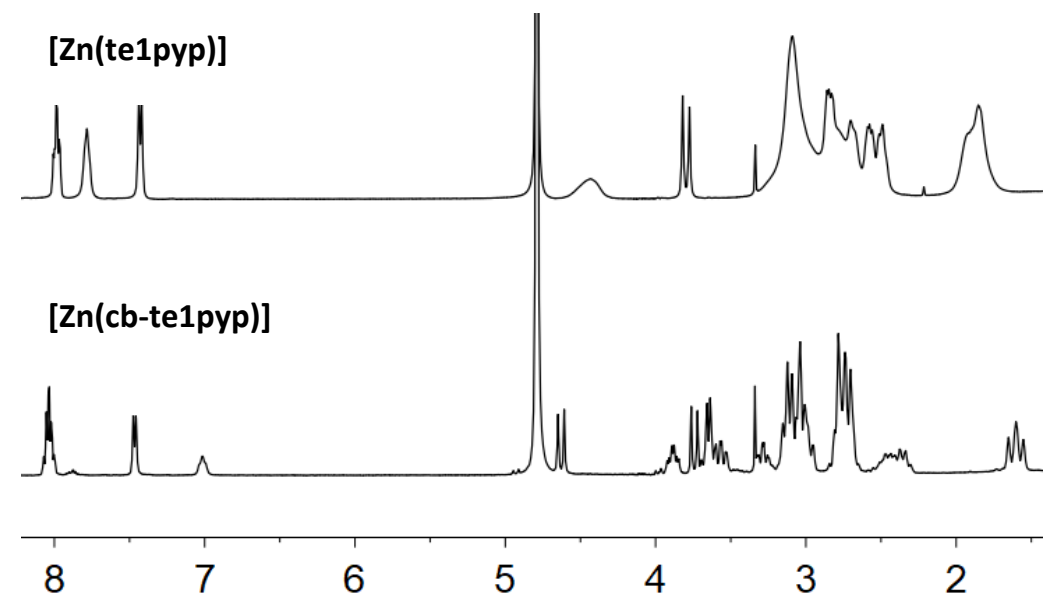

Figure X: ${ }^{1} \mathrm{H}$ NMR spectra $\left(\mathrm{D}_{2} \mathrm{O}, \mathrm{pD} \approx 7.0,400 \mathrm{MHz}, 298 \mathrm{~K}\right)$ of zinc(II) complexes [Zn(te1pyp)] and [Zn(cb-te1pyp)]

EPR analysis. The spin-state of the copper(II) complexes was investigated by electron paramagnetic resonance (EPR) spectroscopy. Complexes were studied in frozen glass (1:1 $\mathrm{H}_{2} \mathrm{O} / \mathrm{DMF}, 150 \mathrm{~K}, \mathrm{X}$-band) and the EPR spectra of the complexes [Cu(te1pyp)] and [Cu(cb-te1pyp)] were recorded as their neutral deprotonated forms; simulation of the spectra confirmed the presence of only one observable paramagnetic species (Figure $\mathbf{X}$ ). Both spectra exhibit typical resonances corresponding to the paramagnetic copper(II) ion with elongated axial symmetry, ${ }^{34-37}$ although the spectra indicate a significant difference in copper(II) geometry for each respective complex. The EPR spectra show only characteristic copper hyperfine splitting, with observation of hyperfine coupling $g_{z}$ component for three of the maxima at low-field (Table 2 ), the other being obscured by the second-order portion of the spectra. 


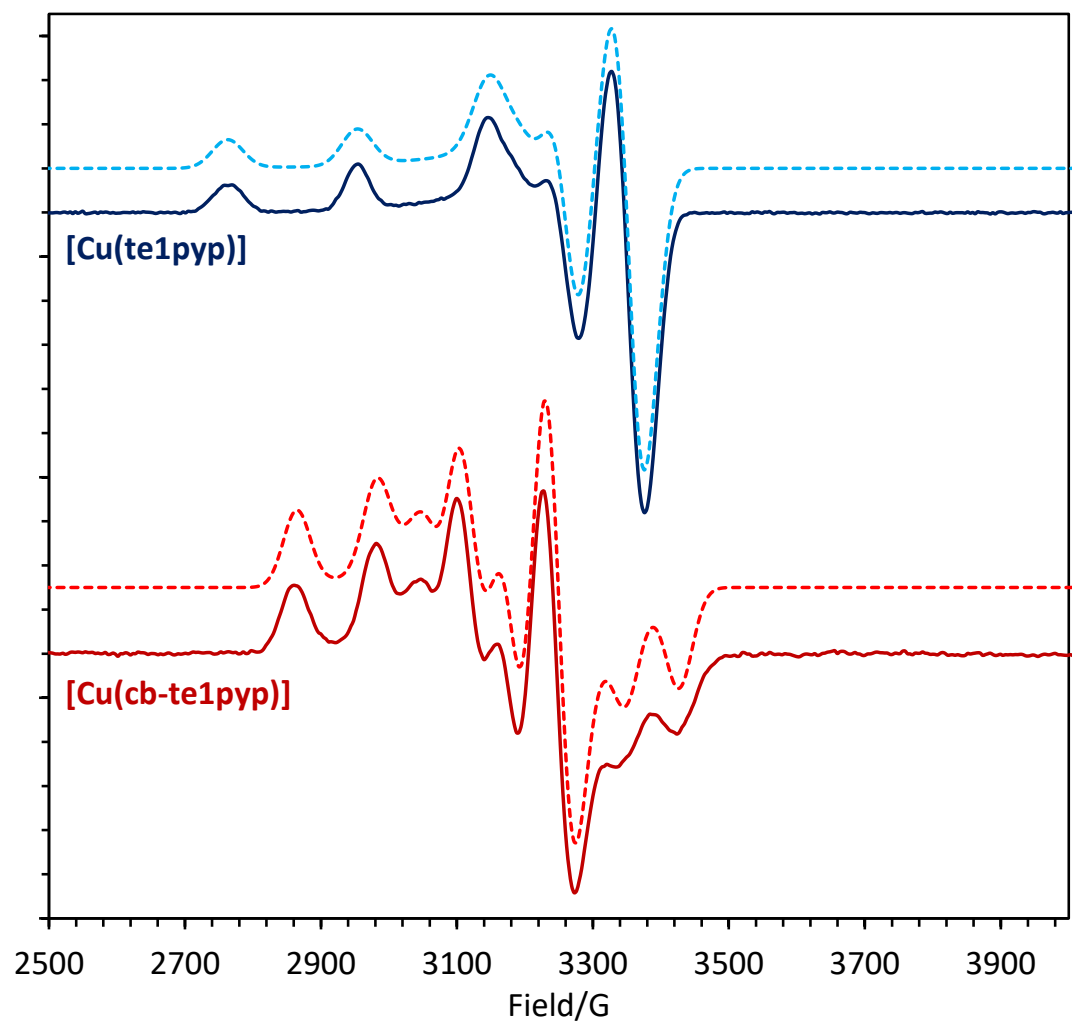

Figure X: X-band EPR spectrum of copper(II) complexes [Cu(te1pyp)] (- experimental; - - simulation) and [Cu(cbte1pyp)] (- experimental; - - - simulation) recorded in frozen aqueous solution (1:1 DMF/ $\left.\mathrm{H}_{2} \mathrm{O}, 1.0 \mathrm{mM} ; 150 \mathrm{~K}\right)$

Additionally, as expected, no superhyperfine coupling was observed to proximal spin-active ${ }^{14} \mathrm{~N}$ or ${ }^{31} \mathrm{P}$ nuclei of the cyclam backbone or phosphonated appendage, indicating the unpaired electron is confined and located exclusively on the copper(II) ion. Simulation of the spectra indicate distorted axial symmetry with three distinct principal values for the $g$ parameter for both complexes. In the case of the less rigid complex [Cu(te1pyp)], the geometry lies closer to an undistorted axial symmetry $\left(g_{\mathrm{x}} \approx g_{\mathrm{y}}<g_{\mathrm{z}}\right)$, while the observation that $\left\{g_{\mathrm{z}}>\left(g_{\mathrm{x}}+g_{\mathrm{y}}\right) / 2\right\}$ and the smallest $g \geq 2.03$,

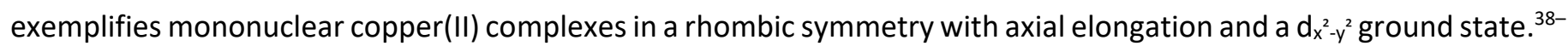
${ }^{40}$ In complexes of this type this is most accurately described as square pyramidal geometry, in good agreement with the solid-state structure (vide supra). This contrasts with the cross-bridged complex [Cu(cb-te1pyp)] which displays inverse parameters $\left(g_{\mathrm{x}}<g_{\mathrm{y}}<g_{\mathrm{z}}\right)$ with a similar $\Delta g$ between each cartesian coordinate value. These properties point towards a $\mathrm{d}_{z}{ }^{2}$ ground state and thus a trigonal prismatic geometry. This observation corroborates well with the $\tau$ values calculated for both [Cu(te1pyp)] and [Cu(cb-te1pypH) $]^{+}$in the single-crystal X-ray studies (vide supra). It can thus be concluded that, qualitatively, both complexes retain their coordination geometry between the solid- and solutionstate.

Table 2: Spectroscopic Parameters for the Copper(II) Complexes of [Cu(te1pyp)] and [Cu(cb-te1pyp)] in aqueous solution (UV-vis measurements performed in $\mathrm{H}_{2} \mathrm{O}(293 \mathrm{~K})$; EPR measurements performed in 1:1 $\mathrm{H}_{2} \mathrm{O}$ /DMF glass (1.0 $\mathrm{mM}, 150 \mathrm{~K} ; A_{\mathrm{i}}$ values quoted in $10^{-4} \mathrm{~cm}^{-1}$ )

\begin{tabular}{|c|c|c|c|c|c|c|c|}
\hline & \multirow{2}{*}{ UV-vis Measurements } & \multicolumn{5}{|c|}{ EPR measurements } \\
\cline { 1 - 5 } & & $\boldsymbol{g}_{\mathrm{x}}$ & $\boldsymbol{g}_{\mathrm{y}}$ & $\boldsymbol{g}_{\mathrm{z}}$ & $\boldsymbol{A}_{\mathrm{x}}$ & $\boldsymbol{A}_{\mathrm{y}}$ & $\boldsymbol{A}_{\mathbf{z}}$ \\
\hline [Cu(te1pyp)] & $215(4000), 274(4300), 604(200)$ & 2.049 & 2.031 & 2.181 & 41.9 & 15.6 & 194.2 \\
\hline$[$ [Cu(cb-te1pyp)] & $229(3500), 286(4000), 555(200), 937(135)$ & 2.185 & 2.105 & 2.005 & 121.1 & 58.1 & 64.7 \\
\hline
\end{tabular}


Acido-Basic Properties. Detailed interpretation of the physico-chemical data on the cupric complexes with te1pyp and cb-te1pyp requires the characterization of the protonation pattern of the ligands, at least in the $\mathrm{pH}$ range relevant to the targeted application (i.e., PET imaging). We therefore investigated the acido-basic properties of the ligands in the $\mathrm{pH}$ range 2.0-11.5 by various techniques. Both te1pyp and cb-te1pyp display four cyclam amino functions, one pyridine and one phosphonate $-\mathrm{PO}_{3}{ }^{2-}$ moiety. Potentiometric measurements (1-2 mM solutions) were first performed to characterize and quantify the majority of the seven protonation sites (ESI, Figures S1 and S3). Some of the protonation constants were indeed difficult to measure with high accuracy due to their low values $\left(\log K^{H}<<2\right.$, vide infra). Table 3 summarises the data resulting from the statistical processing of the potentiometric data. Three protonation constants were determined for te1pyp, while only two $p K_{\mathrm{a}}$ values were accurately calculated for its crossbridged analogue cb-te1pyp.

Table 3. Protonation constants $\left(\log K_{\mathrm{lh}}\right)^{a}$ for ligands te1pyp and cb-te1pyp compared to literature data reported for closely related systems.

\begin{tabular}{|c|c|c|c|c|c|c|c|c|}
\hline \multicolumn{9}{|c|}{$\log K_{\operatorname{lh}}( \pm 3 \sigma)$} \\
\hline \multicolumn{2}{|c|}{ Equilibrium / Constant } & te1pyp & cb-te1pyp & te1pa ${ }^{13}$ & cb-te1pa ${ }^{14}$ & cyclam $^{41}$ & cb-cyclam ${ }^{27}$ & te2p $p^{42}$ \\
\hline $\mathrm{L}+\mathrm{H} \leftrightarrows \mathrm{LH}$ & $\log K_{11}$ & $11.04(3)^{b, e}$ & $\mathrm{~g}$ & $11.55(1)^{\mathrm{e}}$ & $\mathrm{g}$ & $11.29^{\mathrm{e}}$ & $12.42^{\mathrm{e}}$ & \\
\hline $\mathrm{LH}+\mathrm{H} \leftrightarrows \mathrm{LH}_{2}$ & $\log K_{12}$ & $10.30(3)^{\mathrm{b}, \mathrm{e}}$ & $\begin{array}{c}11.38(3)^{\mathrm{b}, \mathrm{e}} \\
11.3(6)^{\mathrm{c}, \mathrm{e}}\end{array}$ & $10.11(1)^{e}$ & $10.13(5)^{\mathrm{e}}$ & $10.19^{e}$ & $10.20^{e}$ & \\
\hline \multicolumn{2}{|c|}{ Mean. $\left(\log K_{11} ; \log K_{12}\right)$} & $10.98(6)^{c, e}$ & na & & & & & \\
\hline$L+2 H \leftrightarrows L H_{2}$ & $\log \beta_{12}$ & & & & & & & $26.41^{e}$ \\
\hline \multirow[t]{2}{*}{$\mathrm{LH}_{2}+\mathrm{H} \leftrightarrows \mathrm{LH}_{3}$} & $\log K_{13}$ & $5.85(5)^{b, d}$ & $5.41(2)^{b, d}$ & $2.71(1)^{f}$ & $2.43(7)^{f}$ & $1.61^{\mathrm{e}}$ & & $6.78^{d}$ \\
\hline & & $5.93(6)^{c, d}$ & $5.3(6)^{c, d}$ & & & & & \\
\hline $\mathrm{LH}_{3}+\mathrm{H} \leftrightarrows \mathrm{LH}_{4}$ & $\log K_{14}$ & & & $1.7(1)^{\mathrm{e}}$ & & $1.91^{\mathrm{e}}$ & & $5.36^{d}$ \\
\hline $\mathrm{LH}_{2}+2 \mathrm{H} \leftrightarrows \mathrm{LH}_{4}$ & $\log K_{13}+\log K_{13}$ & & & & & & $1.39^{\mathrm{e}}$ & \\
\hline $\mathrm{LH}_{4}+\mathrm{H} \leftrightarrows \mathrm{LH}_{5}$ & $\log K_{15}$ & & & & & & & 1.15 \\
\hline
\end{tabular}

$\bar{a}$ Values in parentheses are standard deviations $(3 \sigma)$ in the last significant digit. $I=0.1 \mathrm{M}(\mathrm{NaCl}) ; T=298 \mathrm{~K}(2) .{ }^{b}$ potentiometry. ${ }^{c} \mathrm{Absorption} v s$. pH titrations. $K_{\mathrm{lh}}=\left[\mathrm{Ll}_{\mathrm{l}} \mathrm{H}_{\mathrm{h}}\right] /\left[\mathrm{L}_{\mathrm{l}} \mathrm{H}_{\mathrm{h}-1}\right][\mathrm{H}] .{ }^{d}$ phosphonate units. ${ }^{e}$ cyclam amino units. ${ }^{f}$ carboxylate units. Charges omitted for the sake of clarity. na $=$ not applicable. ${ }^{g}$ Too high to be determined.

For te1pyp, the two highest protonation constants ( $\log K_{1 \mathrm{H}}=11.04(3)$ and $\left.\log K_{2 \mathrm{H}}=10.30(3)\right)$ were attributed to two secondary amines of the tetraazamacrocyle, in excellent agreement with related systems such as cyclam $\left(\log K_{11}=\right.$ 11.29 and $\log K_{12}=10.19(1),{ }^{41} \log K_{11}=11.585(5)$ and $\left.\log K_{12}=10.624(4)^{43}\right)$ or te1pa $\left(\log K_{11}=11.55(1)\right.$ and $\log K_{12}=$ $10.11(1))^{13}$. The $\mathrm{p} K_{\mathrm{a}}$ values of the two remaining amines were estimated to be significantly lower than 2.5 (e.g., $\log K_{13}$ $=2.41^{43} / 1.91^{41}$ and $\log K_{14}=1.61$ for cyclam ${ }^{41,43}$ ) as the consequence of electrostatic repulsion from ammonium cations. In the case of cross-bridged scaffolds, proton sponge character (i.e., stabilization of the first proton by intramolecular hydrogen bonds and solvation effects) has been well-described in the literature, ${ }^{44-48}$ resulting in very high $p K_{\mathrm{a}}$ values for the first protonation equilibrium of the tetraazamacrocycle. The cross-bridged analogue cb-te1pyp does not stand out from this trend as evidenced by the inability to determine the first protonation constant of the cyclam scaffold. Only the second protonation constant $\left(\log K_{12}=11.38(3)\right)$ was accurately evaluated and its value was found to be one order of magnitude higher than those determined for closely related derivatives (cb-cyclam, $\log K_{12}=10.20^{27}$ and $\mathbf{c b}$ - 
te1pa $\left.{ }^{14}, \log K_{12}=10.13(5)\right)$ suggesting additional stabilization by the phosphonate unit. Similarly to te1pyp, the $\mathrm{p} K_{\mathrm{a}}$ values of the two other amino function of the tetraazamacrocycle were estimated to be $<<2.5$.

The following protonation constant of te1pyp $\left(\log K_{13}=5.85(5)\right)$ and cb-te1pyp $\left(\log K_{13}=5.41(2)\right)$ was assigned to the first protonation constant of the phosphonate $-\mathrm{PO}_{3}{ }^{2-}$ units (i.e., $\mathrm{RPO}_{3}{ }^{2-}+\mathrm{H}^{+} \leftrightarrows \mathrm{RPO}_{3} \mathrm{H}^{-}$). Interestingly, these $\mathrm{pK}$ are almost one order of magnitude lower than observed for other phosphonate function, ${ }^{49}$ even in the case of pyridylphosphonic acids. ${ }^{31,50}$ The second protonation constant of the monoprotonated phosphonate groups (i.e., $\mathrm{RPO}_{3} \mathrm{H}^{-}+\mathrm{H}^{+} \leftrightarrows \mathrm{RPO}_{3} \mathrm{H}_{2}$ ) was estimated to be very low $(<<2)$. For te1pyp or cb-te1pyp, the protonation constant of the pyridyl unit cannot be assessed and their $\log K_{14}$ values were estimated to be $\ll 2$. This is consistent with the values determined for the closely related carboxylate analogues te1pa $\left(\log K_{14}=1.7(1)\right)^{13}$ and cb-te1pa $\left(\log K_{14}\right.$ not determined $)^{14}$. According to the protonation diagrams established in this work, the two ligands predominate as neutral zwitterionic species ( $\mathrm{H}_{2}$ te1pyp and $\mathrm{H}_{2}$ cb-te1pyp respectively) at $\mathrm{pH} 7.0$ (Figure $\mathrm{X}$ ), with the tetraazamacrocylic scaffold bearing two positive charges, and the phosphonate unit being under its dianionic form.

Further information was obtained from absorption versus $\mathrm{pH}$ titrations ( $\lambda_{\mathrm{abs}}=220-400 \mathrm{~nm}$, ESI, Figures S2 and S4). For te1pyp or cb-te1pyp, marked spectral variations were observed in neutral to acidic $\mathrm{pH}$ range (and to lesser extend under basic conditions) in line with the (de)protonation of the phosphonate-pyridine substituent (i.e., pyridine is the main chromophore with $\pi-\pi^{*}$ transitions centered at 265-270 nm and $\varepsilon \approx 10^{4} \mathrm{M}^{-1} \mathrm{~cm}^{-1}$ ). For both chelators, the statistical processing of the spectrophotometric and potentiometric data allowed accurate evaluation of two protonation constants. The most basic protonation constant (i.e., mean value between log $K_{11}$ and $\log K_{12}$; significant spectral variation at $225 \mathrm{~nm}$ related to the amine $n-\sigma^{*}$ transitions) of te1pyp was easily assigned to two of the cyclam ionizable sites. For cb-te1pyp, the protonation constant determined $\left(\log K_{12}=11.3(6)\right)$ most likely corresponds to the second protonation equilibrium and is in excellent agreement with that determined by potentiometry $\left(\log K_{12}=\right.$ $11.38(3))$. The second protonation constant measured for te1pyp $\left(\log K_{12}=5.96(6)\right)$ or cb-te1pyp $\left(\log K_{12}=5.3(6)\right)$ can be attributed to the phosphonate unit and its value corresponds very well to that determined previously (te1pyp, log $K_{12}=5.85(5)$ and cb-te1pyp, $\left.\log K_{12}=5.41(2)\right)$. The protonation of these phosphonate units therefore influences the pyridine transitions, as indicated by the significant spectral variations measured at neutral to weakly acidic $\mathrm{pH}$ at 270 $\mathrm{nm}$.
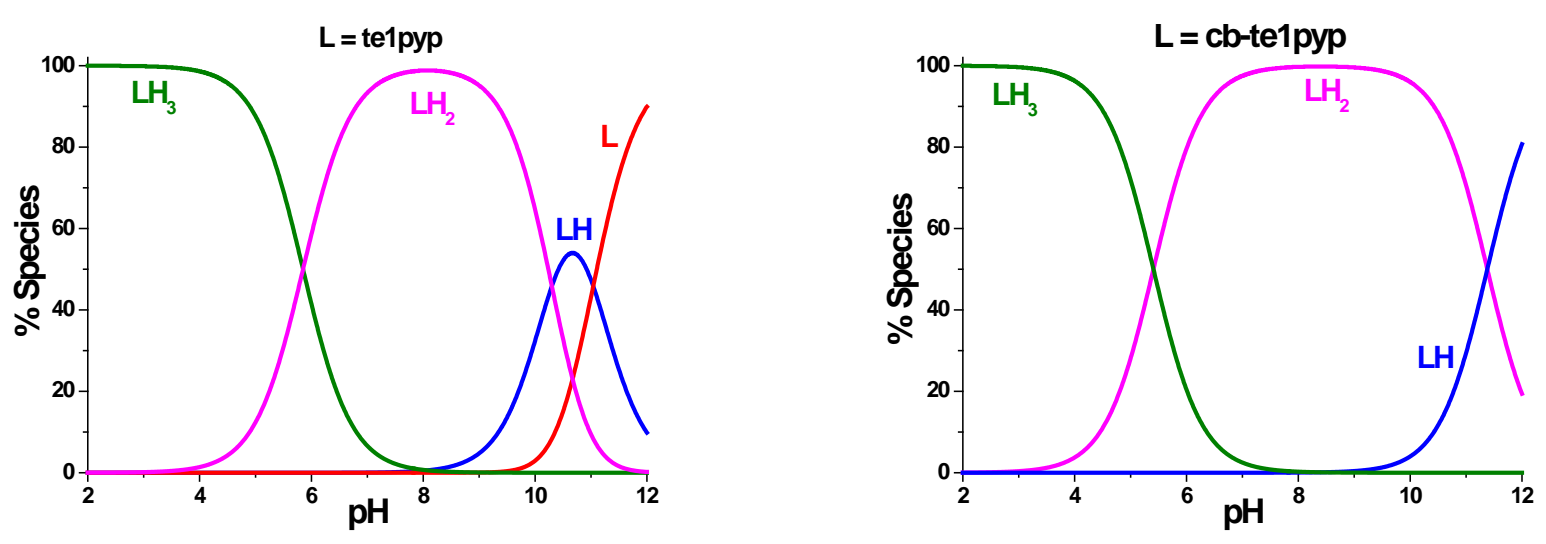

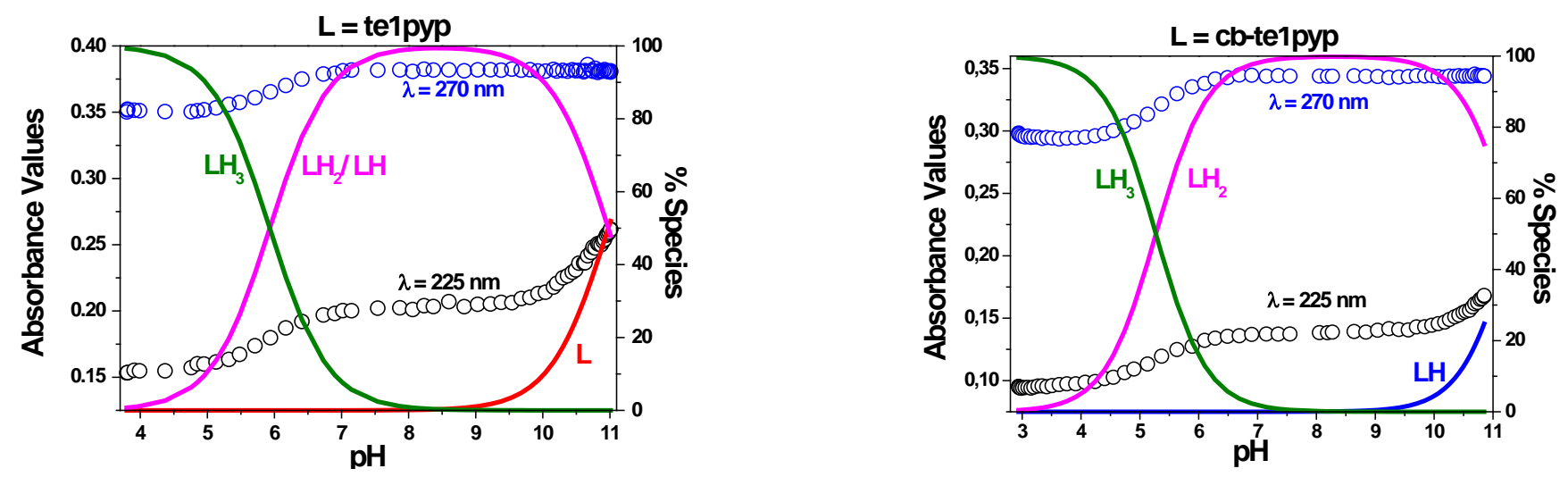

Figure X. Distribution diagrams of the protonated species of te1pyp (left) and cb-te1pyp (right) in solution. Top : from potentiometry; bottom : from absorption versus $\mathrm{pH}$ data, compared to the variation of the absorbance at 270 $\mathrm{nm}$ and $225 \mathrm{~nm}$ as a function of the $\mathrm{pH}$.

$\mathrm{Cu}(I I)$ coordination properties of te1pyp and cb-te1pyp. The stability constants of the cupric complexes with te1pyp and cb-te1pyp were first assessed by potentiometric means (ESI, Figures S5-S8). The statistical analyses of the potentiometric data allowed the determination of the resulting stability constants that are gathered in Table 3 . Only the expected monocupric monochelates were evidenced in agreement with the preliminary LC-ESI-MS studies (vide supra). For te1pyp, the stability constant was too high to be determined directly and accurately. To overcome this problem, the formal stability constant for the formation of [Cu(te1pyp)] was evaluated from a UV-Vis. absorption spectrophotometric titration carried out under acidic conditions ( $\mathrm{pH}=1.53, \mathrm{ESI}$, Figure S7) to ensure sufficient destabilization of the metal complex. This allowed access to the conditional stability constant $\left(\log K_{\text {cu-teipyp }}^{*}=5.8(4)\right.$ at pH 1.53; the asterisk designates the apparent conditions of pH). The formal stability constant of the [Cu(te1pyp)] complex $\left(\log K_{\text {cu-te1pyp }}=25.49\right)$ was then extrapolated from the conditional stability constant measured at pH 1.53 , the protonation constants of the free ligand te1pyp and of the copper(II) complex (Table 3 and Table 4). ${ }^{51}$ [Cu(te1pyp)] complex was also shown to undergo a protonation equilibrium $\left(\log K_{\text {cu-te1pypH }}=5.12(2)\right)$ under weakly acidic conditions that was attributed to one oxygen atom from the phosphonate moiety, the two other oxygen atoms being involved in the stabilization of the cupric complex through hydrogen bonding with the tetraazamacrocyle as shown by the solidstate structure (Figure $\mathbf{X}$ ). The slight diminution of this protonation constant with respect to the free ligand (Table 4) is in agreement with such an interaction.

Table 4. Logarithms of the global ( $\left.\log \beta_{\mathrm{mlh}}\right)$ and successive $\left(\log K_{\mathrm{mlh}}\right)$ stability and protonation constants for the cupric complexes with te1pyp and cb-te1pyp ${ }^{a}$ compared to literature data reported for closely related systems.

\begin{tabular}{|c|c|c|c|c|c|c|c|c|}
\hline Equilibrium & Constant & te1pyp & cb-te1pyp & te1pa ${ }^{13}$ & $\begin{array}{c}\text { cb- } \\
\text { te1paErreur ! } \\
\text { Signet non } \\
\text { défini. }\end{array}$ & cyclam & $\begin{array}{c}\text { cb- } \\
\text { cyclamErreur ! } \\
\text { Signet non } \\
\text { défini. }\end{array}$ & $\begin{array}{l}\text { te2pErreur ! } \\
\text { Signet non } \\
\text { défini. }\end{array}$ \\
\hline \multicolumn{9}{|c|}{$\log \beta_{\operatorname{mlh}}( \pm 3 \sigma)$} \\
\hline \multirow{3}{*}{$\mathrm{Cu}+\mathrm{L} \leftrightarrows \mathrm{CuL}$} & \multirow{3}{*}{$\log \beta_{110}$} & \multirow{3}{*}{$25.49^{c}$} & \multirow{3}{*}{$\mathrm{g}$} & \multirow{3}{*}{25.5} & & $26.5(1)^{52}$ & \multirow{3}{*}{27.1} & \multirow{3}{*}{25.4} \\
\hline & & & & & $\mathrm{g}$ & $28.1^{53}$ & & \\
\hline & & & & & & $27.2^{54}$ & & \\
\hline $\begin{array}{l}\mathrm{Cu}+\mathrm{L}+\mathrm{H} \leftrightarrows \\
\mathrm{CuLH}\end{array}$ & $\log \beta_{111}$ & \multirow[t]{2}{*}{$30.78(2)^{b, e}$} & & \multirow[t]{2}{*}{$27.67^{f}$} & & & & 32.45 \\
\hline $\begin{array}{l}\mathrm{Cu}+\mathrm{L}+2 \mathrm{H} \\
\mathrm{CuLH}_{2}\end{array}$ & $\log \beta_{112}$ & & & & & & & 37.55 \\
\hline
\end{tabular}




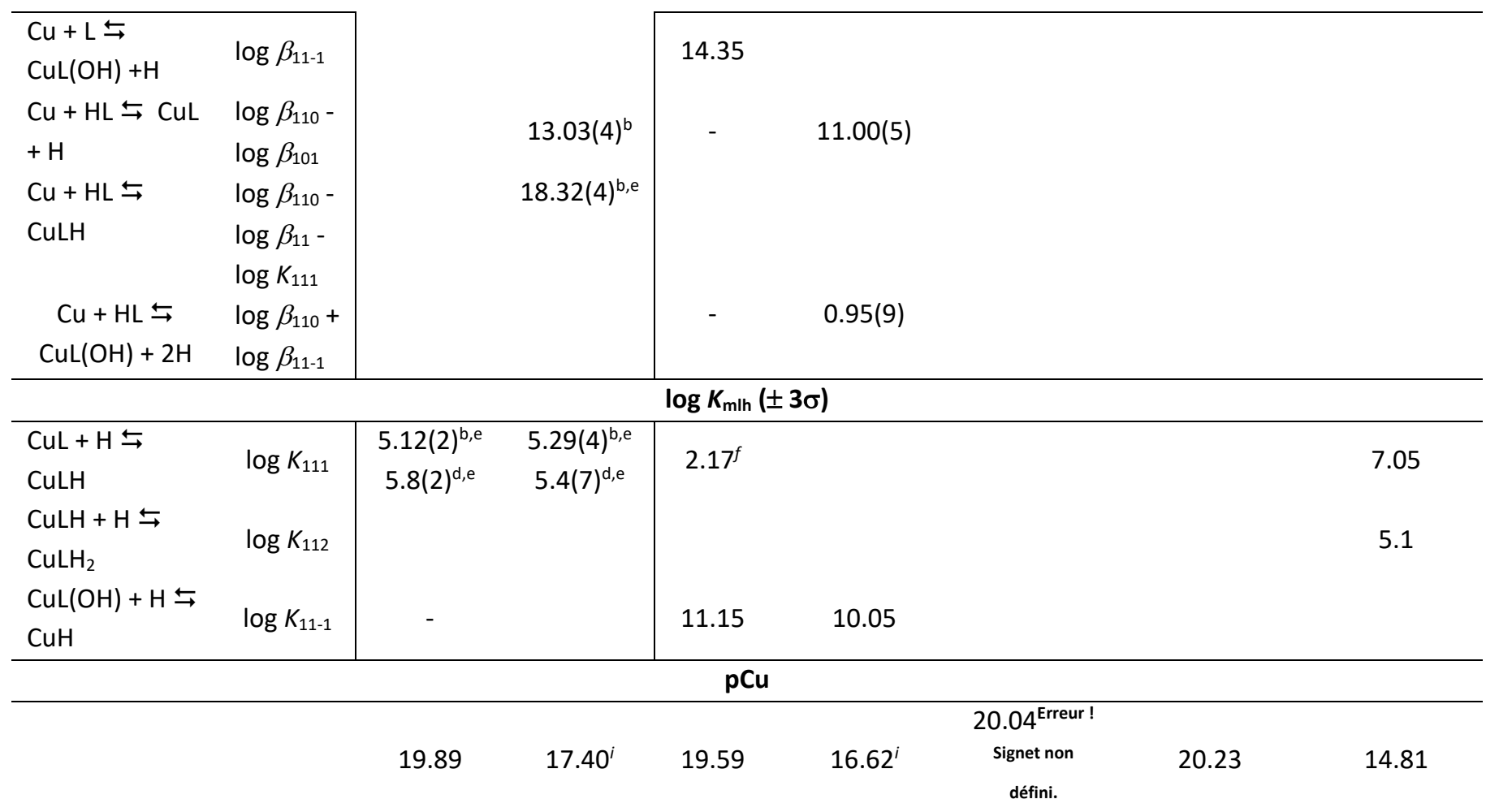

${ }^{a}$ Values in parentheses are standard deviations $(3 \sigma)$ in the last significant digit. $I=0.1 \mathrm{M}(\mathrm{NaCl}) ; T=25 \cdot 0(2) . \beta_{\mathrm{mlh}}=\left[\mathrm{Cum} \mathrm{Ll}_{\mathrm{l}} \mathrm{H}_{\mathrm{h}}\right] /[\mathrm{Cu}]^{\mathrm{m}}[\mathrm{L}]^{l}[\mathrm{H}]^{\mathrm{h}}$. Charges omitted for the sake of clarity. ${ }^{b}$ potentiometry. ${ }^{c}$ Absorption titration at $\mathrm{pH} 1.53 .{ }^{d}$ Absorption versus $\mathrm{pH}$ titration. ${ }^{e}$ phosphonate units. ${ }^{f}$ carboxylate units. na $=$ not applicable. ${ }^{g}$ Too high to be determined. ${ }^{h} \mathrm{pCu}=-\log \left[\mathrm{Cu}^{2+}\right]_{\text {free }}$ for $[\mathrm{L}]=10^{-5} \mathrm{M},[\mathrm{Cu}]=10^{-6} \mathrm{M}$ and pH 7.4, ref ${ }^{55}$. The pCu is a measure of the equilibrium concentrations of free $\mathrm{Cu}^{2+}$ ion. Its value describes the complexing efficiency of the chelating agents and takes into account the difference in basicity of the ligands and stoichiometry of the cupric complexes. $\log K_{\mathrm{Cu}(\mathrm{OH})+}=-6.29$ and $\log K_{\mathrm{Cu}(\mathrm{OH}) 2}=-13.1$ ref. ${ }^{56}$. ${ }^{i}$ calculated with $\log K_{11}$ estimated at 13.

For the potentiometric titrations of the copper(II) complexes with cb-te1pyp, the solutions were prepared in an acidic medium ( $\mathrm{pH} \sim 2.5$ ) and equilibrated for the time necessary to reach fully stabilized measurements thus allowing the determination of the corresponding stability constants. Due to the impossibility of determining the value for the first protonation constant of cb-te1pyp, only the ratio of the constants $K_{\text {cu-cb-te1pyp }} / K_{\text {cb-te1pypH }}$ could be obtained (log $K_{\text {cu-cb- }}$ te1pyp $\left.-\log K_{\mathrm{Cb}-\mathrm{te} 1 \mathrm{pypH}}=13.03(4)\right)$ by this potentiometric approach. To further confirm our hypotheses and evaluate the value of the first protonation constant, a batch titration by UV-Vis. absorption spectrophotometry of cb-te1pyp by $\mathrm{Cu}(I I)$ was carried out under acidic conditions and allowed the determination of the conditional formation constant of the corresponding cupric complex (vide supra for te1pyp, ESI, Figure S10). Only a monocupric monochelate with a conditional stability constant $\log K_{\text {cu-cb-te1pyp }}^{*}=6.3(7)$ at $\mathrm{pH} 2.10$ was evidenced. Assuming the value of first protonation constant to be about $\log K_{\mathrm{cb}-\text { tepypH }}=13$, a theoretical conditional constant $\log K_{\text {cu-cb-te1pyp }}^{*}=5.8$ can be estimated in good agreement within experimental errors with the experimental value. Similarly to its [Cu(te1pyp)] analogue (vide supra), a protonation constant $\left(\log K_{\text {cu-te1pypH }}=5.29(4)\right)$ of the $[\mathrm{Cu}(\mathrm{cb}-$ te1pyp)] complex was measured and most likely corresponds to the protonation of one oxygen atom from the phosphonate moiety in agreement with solid-state data (Figure 2).

In addition to the potentiometric investigations, a UV-Vis. absorption characterization of the monocupric chelates as a function of $\mathrm{pH}$ was also performed (Figure $\mathbf{X}$ and ESI, Figures $\mathrm{S} 6$ and S9). For cb-te1pyp, the prepared solution was set aside enough time to reach equilibrium prior to titration. The high stabilities of both copper(II) complexes even in 
highly acidic media were demonstrated by the presence of spectroscopic signatures such as intense $\mathrm{N} \rightarrow \mathrm{Cu}^{2+}$ Charge Transfer (LMCT) $)^{57-59}$ absorptions in the UV region and weaker $\mathrm{Cu}^{2+} \mathrm{d}-\mathrm{d}$ transitions in the visible spectral window (ESI, Figures S6 and S9). The statistical processing of the absorption and potentiometric data sets allowed the determination of the protonation equilibrium whose $\mathrm{p} K_{\mathrm{a}}$ values $\left(\log K_{\mathrm{Cu}-\mathrm{te} 1 \mathrm{pypH}}=5.8(2)\right.$ for $[\mathrm{Cu}(\mathrm{te} 1 \mathrm{pyp})]$ and $\log K_{\mathrm{Cu}-\mathrm{cb}-\mathrm{te} 1 \mathrm{pypH}}=5.4(7)$ for [Cu(cb-te1pyp)]) were found to be in good agreement with those determined by pure potentiometry (Table 3 ). The spectral characteristics of the $\mathrm{Cu}^{2+} d-d$ transitions $\left(\lambda_{\max }=542 \mathrm{~nm}, \varepsilon^{542}=180 \mathrm{M}^{-1} \mathrm{~cm}^{-1}\right)$ with [Cu(te1pyp)] suggested a distorted square pyramidal geometry in agreement with the equal involvement of the four macrocyclic nitrogen atoms to $\mathrm{Cu}^{2+}$ binding and the apical binding of the $\mathrm{N}$-pyridine unit ((Figure $\mathbf{X}$ and ESI, Figures S6, S7 and S15). ${ }^{60,61}$ On the other hand, it is noteworthy that these stereochemical properties are not markedly influenced by deprotonation of the phosphonate unit, emphasizing the absence of direct interaction of this unit with the metal center. These data are in excellent agreement with those obtained for the copper(II) complexes with the picolinate-derived analogue te1pa $\left(\lambda_{\max }=556 \mathrm{~nm}, \varepsilon^{542}=197 \mathrm{M}^{-1} \mathrm{~cm}^{-1}\right)$ that displays the same coordination behavior with respect to $\mathrm{Cu}(\mathrm{II})$ with no $\mathrm{pH}$ dependence on the $d$ - $d$ transitions. ${ }^{13}$ Incorporation of the cross-bridge to the tetraazamacrocycle scaffold altered significantly the spectral characteristics of the $\mathrm{Cu}^{2+} d-d$ transitions. The $d$ - $d$ transitions of [Cu(cb-te1pyp)] at pH $\sim 2.5$ are indeed characterized by two broad absorption bands in the visible $\left(\lambda_{\max }=597 \mathrm{~nm}, \varepsilon^{597}=250 \mathrm{M}^{-1} \mathrm{~cm}^{-1}\right)$ and NIR $\left(\lambda_{\max }=947 \mathrm{~nm}, \varepsilon^{600}=170 \mathrm{M}^{-1} \mathrm{~cm}^{-1}\right)$ spectral ranges thus demonstrating a significant change of the coordination geometry (Figure 2). Similarly to the picolinate analogue [Cu(cb-te1pa)], the $d-d$ transitions of [Cu(cb-te1pyp)] are not sensitive to the acidity of the medium. Our observations thus match perfectly those obtained for [Cu(cb-te1pa)] ( $\lambda_{\max }$ $=600 \mathrm{~nm}, \varepsilon^{600}=234 \mathrm{M}^{-1} \mathrm{~cm}^{-1}$ and $\left.\lambda_{\max }=938 \mathrm{~nm}, \varepsilon^{938}=152 \mathrm{M}^{-1} \mathrm{~cm}^{-1}\right) \cdot{ }^{14}$ For the latter cupric complex, these spectral features were suggested to arise from a combination of the two geometries occurring in solution, a trigonal bipyramidal (i.e., as observed in the solid state for [Cu(cb-te1pyp)], Figure 2) and a compressed octahedral (i.e. involving weak binding of a solvent molecule or hydroxide ion) geometries. Erreur ! signet non défini. We therefore hypothesize the same properties in solution for the [Cu(cb-te1pyp)] complex.
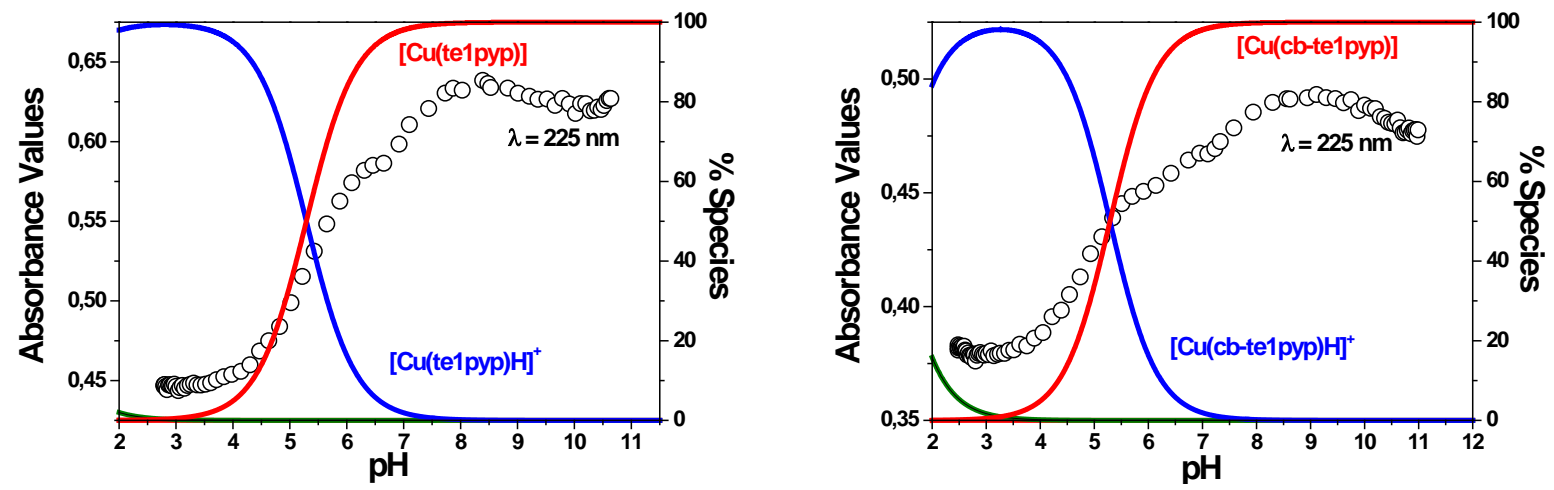

Figure X. Distribution diagrams of the cupric complexes with te1pyp and cb-te1pyp in solution (from potentiometric data) as a function of $\mathrm{pH}$, compared to the variation of the absorbance at $225 \mathrm{~nm}$ as a function of the $\mathrm{pH}$.

To compare the coordination properties of te1pyp and cb-te1pyp with other copper(II) chelators, their pCu values (Table 4) were calculated at $\mathrm{pH}=7.4 .^{55,62}$ These $\mathrm{pCu}$ values measure the equilibrium concentrations of free $\mathrm{Cu}^{2+}$ ion and are defined as: $\mathrm{pCu}=-\log \left[\mathrm{Cu}^{2+}\right]_{\text {free }}$ with $[\mathrm{L}]_{\mathrm{tot}}=10^{-5} \mathrm{M},\left[\mathrm{Cu}^{2+}\right]_{\mathrm{tot}}=10^{-6} \mathrm{M}$. This $\mathrm{pCu}$ value takes into account the characteristics of the ligands that are compared (acido-basic properties of the free ligand and of the metal complexes, stoichiometry of metal complexes, etc) and thus allows a direct comparison of their chelating affinity for a given cation. High pCu values will therefore be a signature of a strong binding affinity of the chelator toward $\mathrm{Cu}^{2+}$. For te1pyp and 
cb-te1pyp, the stability constants and the corresponding pCu values (Table 3) indicate high thermodynamic stabilities of the copper(II) complexes that are suitable for PET imaging techniques. Furthermore, the calculated pCu values (19.89 for te1pyp and 17.40 for cb-te1pyp) are comparable to the prototypical cyclam $(p C u=20.04)$ and its crossbridged analogue cb-cyclam $(\mathrm{pCu}=20.23)$. On the other hand, similar $\mathrm{Cu}(I I)$ coordination properties have been evidenced in this report with the picolinate-derived chelators te1pa $(\mathrm{pCu}=19.59)$ and $\mathbf{c b}$-te1 pa $(\mathrm{pCu}=16.62)$.

Kinetic Stability of the Copper(II) Complexes. The kinetic inertness of such chelates can be estimated through acidassisted dissociation in highly acidic media, in order to compare their properties to parent complexes. The dissociation phenomenon was monitored by following the Cu-centered $d-d$ absorption bands of the complexes under pseudo firstorder conditions in aqueous solutions at $25^{\circ} \mathrm{C}$. [Cu(te1pyp)] and [Cu(cb-te1pyp)] exhibited half-lives of $35 \mathrm{~min}$ and $15.2 \mathrm{~h}$ respectively in $1 \mathrm{M} \mathrm{HCl}$. In addition, [Cu(cb-te1pyp)] showed a half-life of 36 min in $5 \mathrm{M} \mathrm{HCl}$ at $25^{\circ} \mathrm{C}$ (Table 5).

Table 5. Half-life ( $\left.t_{1 / 2}\right)$ values for copper(II) complexes of te1pyp, cb-te1pyp and their picolinates analogues in acidic conditions.

\begin{tabular}{lcccc}
\hline Conditions & te1pyp & cb-te1pyp & $\begin{array}{c}\text { cb- } \\
\text { te1pa }\end{array}$ & $\begin{array}{c}13 \\
\text { te1paErreur ! } \\
\text { Signet non } \\
\text { défini. }\end{array}$ \\
\hline $1 \mathrm{M} \mathrm{HCl}, 25^{\circ} \mathrm{C}$ & $35 \mathrm{~min}$ & $912 \mathrm{~min}$ & $32 \mathrm{~min}$ & \\
$5 \mathrm{M} \mathrm{HCl}, 25^{\circ} \mathrm{C}$ & & $36 \mathrm{~min}$ & & $465 \mathrm{~min}$ \\
\hline
\end{tabular}

The kinetic inertness of [Cu(te1pyp)] is similar to the one of its picolinate analogue [Cu(te1pa)]. In accordance with previously described trends, the corresponding cross-bridged complex [Cu(cb-te1pyp)] presents a much higher inertness owing to the reinforced and preorganized cavity, but remains lower than its picolinate counterpart, evidencing again the detrimental effect of phosphonate moieties in this regard. However, these data provide a good indication towards the safe use in vivo for both complexes.

${ }^{64} \mathrm{Cu}$-Radiolabeling and in vitro stability. Radiolabeling was performed using similar conditions previously described for the picolinate analogues, i.e. $\mathrm{pH} \mathrm{5-6}$ in sodium acetate buffer solutions, and incubation times of 30 minutes at $40^{\circ} \mathrm{C}$ and $85^{\circ} \mathrm{C}$ respectively for te1pyp and cb-te1pyp. Quantitative labeling was observed by C18-silica radio-TLC, and radioHPLC experiments confirmed the purity of the samples (see ESI, Figure S17). To corroborate the kinetic inertness experiments, stability in human serum was also investigated for the least inert $\left[{ }^{64} \mathrm{Cu}\left(\right.\right.$ te1pyp)], with ${ }^{64} \mathrm{Cu}$ acetate and $\left[{ }^{64} \mathrm{Cu}(\right.$ te1 pa) $]$ in buffer solutions as controls (Figure $\mathrm{X}$ ). 


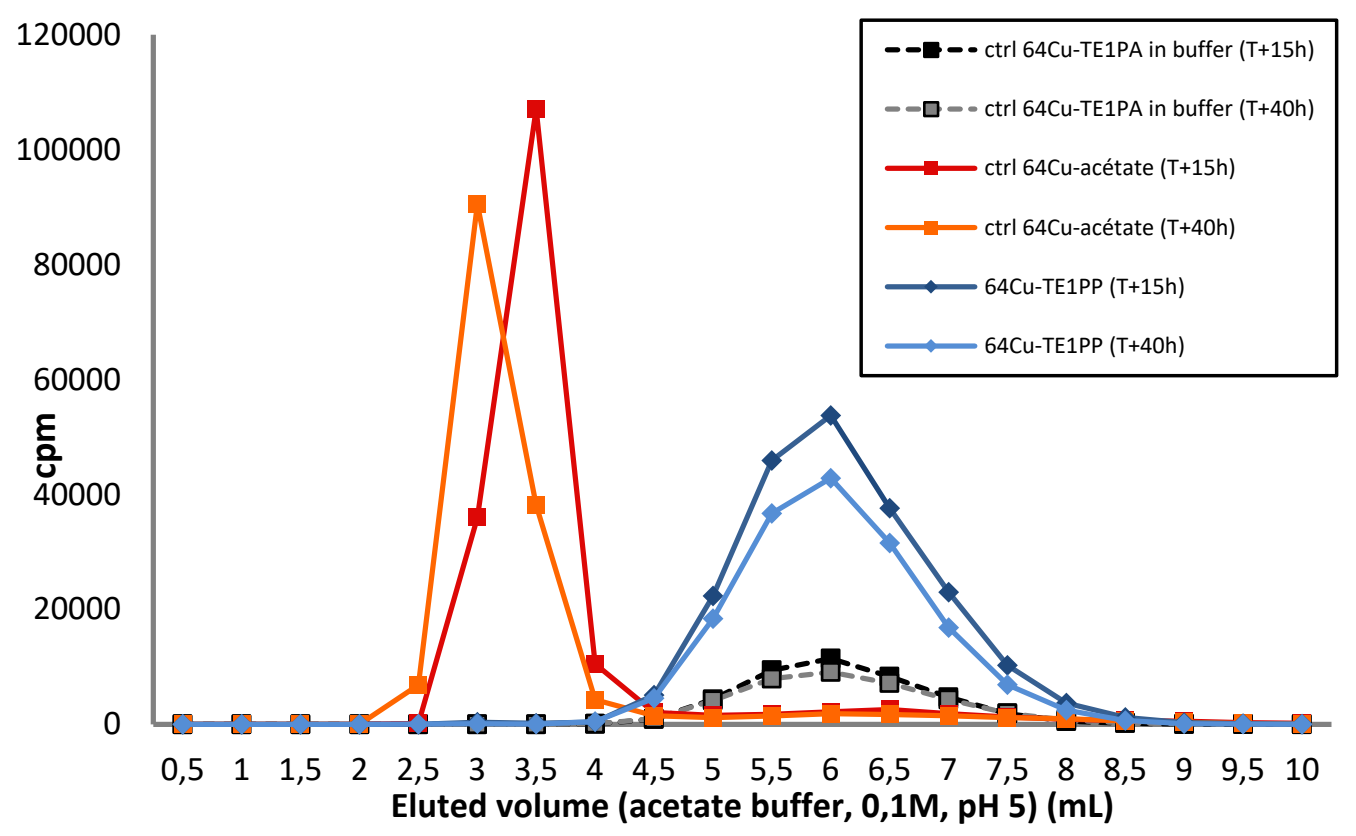

Figure X. Radio-HPLC chromatograms of [ ${ }^{64} \mathrm{Cu}$ (te1pyp)] incubated in human serum for 15 and 40 hours. ${ }^{64} \mathrm{Cu}$ acetate and a solution of $\left[{ }^{64} \mathrm{Cu}(\right.$ te1 1 pyp) $]$ in acetate buffer were used as controls.

After incubation at $37^{\circ} \mathrm{C}$, no dissociation is observed for [ ${ }^{64} \mathrm{Cu}($ te1pyp)] after 15 or 40 hours, as evidenced by the absence of a peak at the retention time free ${ }^{64} \mathrm{Cu}$ acetate (3-3.5 mins) on the radio-HPLC chromatograms. In addition, the complex is eluted with the same retention time as its $\left[{ }^{64} \mathrm{Cu}(\mathrm{te} 1 \mathrm{pa})\right]$ counterpart, furthermore evidencing its preservation. In order to confirm the absence of fixation to proteins and the intact nature of the chelates, a second control was realized by deproteinization of the samples and radio-TLC chromatography with ${ }^{64} \mathrm{Cu}$-acetate and ${ }^{64} \mathrm{Cu}$ (te1pyp) solution in buffer as controls. Again, the preserved complexes were unambiguously evidenced (see ESI, Figure S18). 
In vivo PET imaging and distribution. Owing to the excellent properties of both complexes in vitro, the in vivo behaviour of $\left[{ }^{64} \mathrm{Cu}(\mathrm{te} 1 \mathrm{pyp})\right]$ and $\left[{ }^{64} \mathrm{Cu}(\mathrm{cb}\right.$-te1pyp)] was investigated. XX MBq of complexes were injected to XXX type mice, and PET-CT imaging was conducted at $\mathrm{t}=2 \mathrm{~h}$ post-injection (PI). Very interestingly, and as anticipated for these two phosphonated chelates, the body clearance is fast and mainly through renal elimination, as evidenced by the strong activity in kidneys and bladder (Figure $\mathbf{X}$ ).
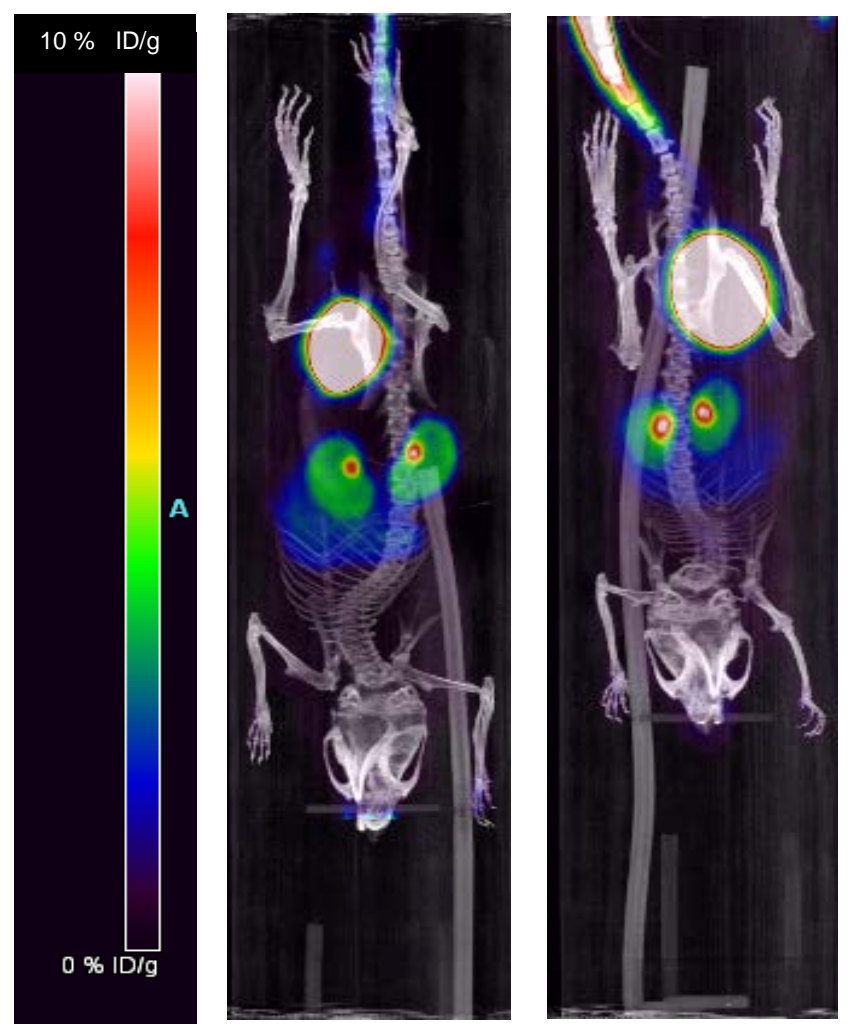

Figure X. PET-CT imaging of XXXXX mice model injected with $\left[{ }^{64} \mathrm{Cu}\left(\right.\right.$ te1pyp) (left) and $\left[{ }^{64} \mathrm{Cu}(\mathrm{cb}-\mathrm{te} 1 \mathrm{pyp})\right]$ (right) at $\mathrm{t}=$ $2 \mathrm{~h}$ post-injection.

However, the most striking feature is related to the very low activity detected in the liver for both chelates, with maximal SUV (Standardized Uptake Value) of ca. 2\% ID/g, which is much lower than what has been described for their carboxylated counterparts, with a SUV of $10,2 \pm 2 \%$ reported at $\mathrm{t}=2 \mathrm{~h}$ PI for $\left[{ }^{64} \mathrm{Cu}(\mathrm{te} 1 \mathrm{pa})\right] .{ }^{15}$ This positive effect can be attributed, as expected, to the difference in charge and lipophillicity brought by phosphonic moieties as compared to their carboxylic counterparts.

\section{Conclusions}

We have been reporting recently the strong potential of te1pa and its bifonctionnal analogues as performant chelating ligands for targeted in vivo ${ }^{64} \mathrm{Cu}-\mathrm{PET}$ imaging. In this work, we have prepared the corresponding phosphonated equivalent of te1pa and its cross-bridge reinforced analogue cb-te1pa, and investigated their coordination properties towards copper(II) by solid-state, spectroscopic and potentiometric techniques. Both novel ligands demonstrated a high affinity for copper(II) and suitable kinetic inertness for in vivo use. Radiolabelling of the ligands was easily achieved in mild conditions, and full stability in human serum was evidenced. However, the biodistribution of the corresponding ${ }^{64} \mathrm{Cu}$ complexes has been improved when compared to their picolinates analogues, with a fast renal elimination 
combined with very low hepatic fixation. Te1pyp and cb-te1pyp corresponding bifonctionnal ligands will thus be considered in future work to enable their use in targeted PET imaging in oncology. Their reduced accumulation in the liver offers a great alternative when compared to their carboxylated congeners, to alter the biodistribution of radiotracers, in particular as antibody-based conjugates are known to have a marked hepatic affinity.

\section{Acknowledgements}

T.T., R.T., R.C.K, T.L.B. and N.L.B. are grateful to the Centre National de la Recherche Scientifique (CNRS) and the Université de Bretagne Occidentale (CEMCA UMR 6521) for financial support.

T.T. and R.C.K. acknowledge Région Bretagne (SAD HypoTrac) for funding, the RSC Research Fund (Grant no. RF190248) for the purchase of equipment, and N. Kervarec from the "Service commun de RMN-RPE" (Universite de Bretagne Occidentale) for EPR measurements.

M.E., V.M. and L.J.C. are grateful to the Centre National de la Recherche Scientifique (CNRS) and the University of Strasbourg (LIMA UMR 7042, IPHC UMR 7178) for financial support.

\section{Experimental (see joint ESI file for now)}

\section{References}

(1) Heiden, M. G. V.; Cantley, L. C.; Thompson, C. B. Understanding the Warburg Effect: The Metabolic Requirements of Cell Proliferation. Science 2009, 324 (5930), 1029-1033.

(2) Belhocine, T.; Spaepen, K.; Dusart, M.; Castaigne, C.; Muylle, K.; Bourgeois, P.; Bourgeois, D.; Dierickx, L.; Flamen, P. 18FDG PET in Oncology: The Best and the Worst (Review). International Journal of Oncology 2006, 28 (5), 1249-1261.

(3) Wadas, T. J.; Wong, E. H.; Anderson, G. R. W. and C. J. Copper Chelation Chemistry and Its Role in Copper Radiopharmaceuticals. Current Pharmaceutical Design 2007, 13 (1), 3-16.

(4) Cai, Z.; Anderson, C. J. Chelators for Copper Radionuclides in Positron Emission Tomography Radiopharmaceuticals. Journal of Labelled Compounds and Radiopharmaceuticals 2014, 57 (4), 224230.

(5) Anderson, C. J.; Ferdani, R. Copper-64 Radiopharmaceuticals for PET Imaging of Cancer: Advances in Preclinical and Clinical Research. Cancer Biotherapy and Radiopharmaceuticals 2009, 24 (4), 379393.

(6) Boswell, C. A.; Sun, X.; Niu, W.; Weisman, G. R.; Wong, E. H.; Rheingold, A. L.; Anderson, C. J. Comparative in Vivo Stability of Copper-64-Labeled Cross-Bridged and Conventional Tetraazamacrocyclic Complexes. J. Med. Chem. 2004, 47 (6), 1465-1474.

(7) Delgado, R.; Félix, V.; Lima, L. M. P.; Price, D. W. Metal Complexes of Cyclen and Cyclam Derivatives Useful for Medical Applications: A Discussion Based on Thermodynamic Stability Constants and Structural Data. Dalton Trans. 2007, No. 26, 2734-2745.

(8) Bass, L. A.; Wang, M.; Welch, M. J.; Anderson, C. J. In Vivo Transchelation of Copper-64 from TETA-Octreotide to Superoxide Dismutase in Rat Liver. Bioconjugate Chem. 2000, 11 (4), 527-532.

(9) Pandya, D. N.; Kim, J. Y.; Park, J. C.; Lee, H.; Phapale, P. B.; Kwak, W.; Choi, T. H.; Cheon, G. J.; Yoon, Y.-R.; Yoo, J. Revival of TE2A; a Better Chelate for Cu(II) Ions than TETA? Chem. Commun. 2010, 46 (20), 3517-3519.

(10) Bhatt, N.; Soni, N.; Ha, Y. S.; Lee, W.; Pandya, D. N.; Sarkar, S.; Kim, J. Y.; Lee, H.; Kim, S. H.; An, G. I.; et al. Phosphonate Pendant Armed Propylene Cross-Bridged Cyclam: Synthesis and Evaluation as a Chelator for Cu-64. ACS Med. Chem. Lett. 2015, 6 (11), 1162-1166. 
(11) Wadas, T. J.; Anderson, C. J. Radiolabeling of TETA- and CB-TE2A-Conjugated Peptides with Copper-64. Nature Protocols 2006, 1 (6), 3062-3068.

(12) Boswell, C. A.; McQuade, P.; Weisman, G. R.; Wong, E. H.; Anderson, C. J. Optimization of Labeling and Metabolite Analysis of Copper-64-Labeled Azamacrocyclic Chelators by Radio-LC-MS. Nuclear Medicine and Biology 2005, 32 (1), 29-38.

(13) Lima, L. M. P.; Esteban-Gómez, D.; Delgado, R.; Platas-Iglesias, C.; Tripier, R. Monopicolinate Cyclen and Cyclam Derivatives for Stable Copper(II) Complexation. Inorg. Chem. 2012, 51 (12), 6916-6927.

(14) Lima, L. M. P.; Halime, Z.; Marion, R.; Camus, N.; Delgado, R.; Platas-Iglesias, C.; Tripier, R. Monopicolinate Cross-Bridged Cyclam Combining Very Fast Complexation with Very High Stability and Inertness of Its Copper(II) Complex. Inorg. Chem. 2014, 53 (10), 5269-5279.

(15) Frindel, M.; Camus, N.; Rauscher, A.; Bourgeois, M.; Alliot, C.; Barré, L.; Gestin, J.-F.; Tripier, R.; Faivre-Chauvet, A. Radiolabeling of HTE1PA: A New Monopicolinate Cyclam Derivative for Cu-64 Phenotypic Imaging. In Vitro and in Vivo Stability Studies in Mice. Nuclear Medicine and Biology 2014, 41, e49-e57.

(16) Halime, Z.; Frindel, M.; Camus, N.; Orain, P.-Y.; Lacombe, M.; Chérel, M.; Gestin, J.-F.; FaivreChauvet, A.; Tripier, R. New Synthesis of Phenyl-Isothiocyanate C-Functionalised Cyclams. Bioconjugation and 64Cu Phenotypic PET Imaging Studies of Multiple Myeloma with the Te2a Derivative. Org. Biomol. Chem. 2015, 13 (46), 11302-11314.

(17) Frindel, M.; Saëc, P. L.; Beyler, M.; Navarro, A.-S.; Saï-Maurel, C.; Alliot, C.; Chérel, M.; Gestin, J.F.; Faivre-Chauvet, A.; Tripier, R. Cyclam Te1pa for 64Cu PET Imaging. Bioconjugation to Antibody, Radiolabeling and Preclinical Application in Xenografted Colorectal Cancer. RSC Adv. 2017, 7 (15), 9272-9283.

(18) Le Bihan, T.; Navarro, A.-S.; Bris, N. L.; Saëc, P. L.; Gouard, S.; Haddad, F.; Gestin, J.-F.; Chérel, M.; Faivre-Chauvet, A.; Tripier, R. Synthesis of C-Functionalized TE1PA and Comparison with Its Analogues. An Example of Bioconjugation on 9E7.4 MAb for Multiple Myeloma 64Cu-PET Imaging. Org. Biomol. Chem. 2018, 16 (23), 4261-4271.

(19) Ševčík, R.; Vaněk, J.; Michalicová, R.; Lubal, P.; Hermann, P.; Santos, I. C.; Santos, I.; Campello, M. P. C. Formation and Decomplexation Kinetics of Copper(II) Complexes with Cyclen Derivatives Having Mixed Carboxylate and Phosphonate Pendant Arms. Dalton Trans. 2016, 45 (32), 1272312733.

(20) Kotek, J.; Lubal, P.; Hermann, P.; Císařová, I.; Lukeš, I.; Godula, T.; Svobodová, I.; Táborský, P.; Havel, J. High Thermodynamic Stability and Extraordinary Kinetic Inertness of Copper(II) Complexes with 1,4,8,11-Tetraazacyclotetradecane-1,8-Bis(Methylphosphonic Acid): Example of a Rare Isomerism between Kinetically Inert Penta- and Hexacoordinated Copper(II) Complexes. Chemistry A European Journal 2003, 9 (1), 233-248.

(21) Svobodová, I.; Havlíčková, J.; Plutnar, J.; Lubal, P.; Kotek, J.; Hermann, P. Metal Complexes of 4,11Dimethyl-1,4,8,11-Tetraazacyclotetradecane-1,8-Bis(Methylphosphonic Acid) - Thermodynamic and Formation/Decomplexation Kinetic Studies. European Journal of Inorganic Chemistry 2009, 2009 (24), 3577-3592.

(22) Stigers, D. J.; Ferdani, R.; Weisman, G. R.; Wong, E. H.; Anderson, C. J.; Golen, J. A.; Moore, C.; Rheingold, A. L. A New Phosphonate Pendant-Armed Cross-Bridged Tetraamine Chelator Accelerates Copper(II) Binding for Radiopharmaceutical Applications. Dalton Trans. 2010, 39 (7), 1699-1701.

(23) Dale, A. V.; Pandya, D. N.; Kim, J. Y.; Lee, H.; Ha, Y. S.; Bhatt, N.; Kim, J.; Seo, J. J.; Lee, W.; Kim, S. H.; et al. Non-Cross-Bridged Tetraazamacrocyclic Chelator for Stable 64Cu-Based Radiopharmaceuticals. ACS Med. Chem. Lett. 2013, 4 (10), 927-931.

(24) Bass, L. A.; Wang, M.; Welch, M. J.; Anderson, C. J. In Vivo Transchelation of Copper-64 from TETA-Octreotide to Superoxide Dismutase in Rat Liver. Bioconjugate Chem. 2000, 11 (4), 527-532.

(25) Ferdani, R.; Stigers, D. J.; Fiamengo, A. L.; Wei, L.; Li, B. T. Y.; Golen, J. A.; Rheingold, A. L.; Weisman, G. R.; Wong, E. H.; Anderson, C. J. Synthesis, Cu(II) Complexation, 64Cu-Labeling and Biological Evaluation of Cross-Bridged Cyclam Chelators with Phosphonate Pendant Arms. Dalton Trans. 2012, 41 (7), 1938-1950.

(26) Dale, A. V.; An, G. I.; Pandya, D. N.; Ha, Y. S.; Bhatt, N.; Soni, N.; Lee, H.; Ahn, H.; Sarkar, S.; Lee, W.; et al. Synthesis and Evaluation of New Generation Cross-Bridged Bifunctional Chelator for 64Cu Radiotracers. Inorg. Chem. 2015, 54 (17), 8177-8186. 
(27) Sun, X.; Wuest, M.; Weisman, G. R.; Wong, E. H.; Reed, D. P.; Boswell, C. A.; Motekaitis, R.; Martell, A. E.; Welch, M. J.; Anderson, C. J. Radiolabeling and In Vivo Behavior of Copper-64Labeled Cross-Bridged Cyclam Ligands. J. Med. Chem. 2002, 45 (2), 469-477.

(28) Sun, X.; Wuest, M.; Kovacs, Z.; Sherry, D. A.; Motekaitis, R.; Wang, Z.; Martell, A. E.; Welch, M. J.; Anderson, C. J. In Vivo Behavior of Copper-64-Labeled Methanephosphonate Tetraaza Macrocyclic Ligands. J Biol Inorg Chem 2003, 8 (1), 217-225.

(29) Salaam, J.; Tabti, L.; Bahamyirou, S.; Lecointre, A.; Hernandez Alba, O.; Jeannin, O.; Camerel, F.; Cianférani, S.; Bentouhami, E.; Nonat, A. M.; et al. Formation of Mono- and Polynuclear Luminescent Lanthanide Complexes Based on the Coordination of Preorganized Phosphonated Pyridines. Inorg. Chem. 2018, 57 (10), 6095-6106.

(30) Nonat, A.; Bahamyirou, S.; Lecointre, A.; Przybilla, F.; Mély, Y.; Platas-Iglesias, C.; Camerel, F.; Jeannin, O.; Charbonnière, L. J. Molecular Upconversion in Water in Heteropolynuclear Supramolecular Tb/Yb Assemblies. J. Am. Chem. Soc. 2019, 141 (4), 1568-1576.

(31) Knighton, R. C.; Soro, L. K.; Troadec, T.; Mazan, V.; Nonat, A. M.; Elhabiri, M.; Saffon-Merceron, N.; Djenad, S.; Tripier, R.; Charbonnière, L. J. Formation of Heteropolynuclear Lanthanide Complexes Using Macrocyclic Phosphonated Cyclam-Based Ligands. Inorg. Chem. 2020, 59 (14), 10311-10327.

(32) Herrero, C.; Quaranta, A.; Ghachtouli, S. E.; Vauzeilles, B.; Leibl, W.; Aukauloo, A. Carbon Dioxide Reduction via Light Activation of a Ruthenium-Ni(Cyclam) Complex. Phys. Chem. Chem. Phys. 2014, 16 (24), 12067-12072.

(33) Addison, A. W.; Rao, T. N.; Reedijk, J.; Rijn, J. van; Verschoor, G. C. Synthesis, Structure, and Spectroscopic Properties of Copper(II) Compounds Containing Nitrogen-Sulphur Donor Ligands; the Crystal and Molecular Structure of Aqua[1,7-Bis(N-Methylbenzimidazol-2'-Yl)-2,6-

Dithiaheptane]Copper(II) Perchlorate. J. Chem. Soc., Dalton Trans. 1984, No. 7, 1349-1356.

(34) Lever, A. B. P. Inorganic Electronic Spectroscopy, 2nd Ed.; Elsevier, New York, 1984; pp 554-572.

(35) Hathaway, B. J. Copper. Coordination Chemistry Reviews 1983, 52, 87-169.

(36) Hathaway, B. J.; Tomlinson, A. A. G. Copper(II) Ammonia Complexes. Coordination Chemistry Reviews 1970, 5 (1), 1-43.

(37) Hathaway, B. J.; Billing, D. E. The Electronic Properties and Stereochemistry of Mono-Nuclear Complexes of the Copper(II) Ion. Coordination Chemistry Reviews 1970, 5 (2), 143-207.

(38) Bertini, I.; Gatteschi, D.; Scozzafava, A. Jahn-Teller Distortions of Tris(Ethylenediamine)Copper(II) Complexes. Inorg. Chem. 1977, 16 (8), 1973-1976.

(39) Halcrow, M. A. Interpreting and Controlling the Structures of Six-Coordinate Copper(II) Centres When Is a Compression Really a Compression? Dalton Trans. 2003, No. 23, 4375-4384.

(40) Garribba, E.; Micera, G. The Determination of the Geometry of Cu(II) Complexes: An EPR Spectroscopy Experiment. J. Chem. Educ. 2006, 83 (8), 1229.

(41) Hancock, R. D.; Motekaitis, R. J.; Mashishi, J.; Cukrowski, I.; Reibenspies, J. H.; Martell, A. E. The Unusual Protonation Constants of Cyclam. A Potentiometric, Crystallographic and Molecular Mechanics Study. J. Chem. Soc., Perkin Trans. 2 1996, No. 9, 1925-1929.

(42) Svobodová, I.; Lubal, P.; Plutnar, J.; Havlíčková, J.; Kotek, J.; Hermann, P.; Lukeš, I. Thermodynamic, Kinetic and Solid-State Study of Divalent Metal Complexes of 1,4,8,11-Tetraazacyclotetradecane (Cyclam) Bearing Two Trans (1,8-)Methylphosphonic Acid Pendant Arms. Dalton Trans. 2006, No. 43, 5184-5197.

(43) Micheloni, M.; Sabatini, A.; Paoletti, P. Solution Chemistry of Macrocycles. Part 1. Basicity Constants of 1,4,8,11-Tetra-Azacyclotetradecane, 1,4,8,12-Tetra-Azacyclopentadecane, and 1,4,8,11Tetramethyl-1,4,8,11-Tetra-Azacyclotetradecane. J. Chem. Soc., Perkin Trans. 2 1978, No. 8, 828830.

(44) Esteves, C. V.; Lamosa, P.; Delgado, R.; Costa, J.; Désogère, P.; Rousselin, Y.; Goze, C.; Denat, F. Remarkable Inertness of Copper(II) Chelates of Cyclen-Based Macrobicycles with Two Trans-NAcetate Arms. Inorg. Chem. 2013, 52 (9), 5138-5153.

(45) Weisman, G. R.; Rogers, M. E.; Wong, E. H.; Jasinski, J. P.; Paight, E. S. Cross-Bridged Cyclam. Protonation and Lithium Cation ( $\mathrm{Li}+)$ Complexation in a Diamond-Lattice Cleft. J. Am. Chem. Soc. 1990, 112 (23), 8604-8605.

(46) Bencini, A.; Bianchi, A.; Bazzicalupi, C.; Ciampolini, M.; Fusi, V.; Micheloni, M.; Nardi, N.; Paoli, P.; Valtancoli, B. Proton Inclusion Properties of a New Azamacrocycle. Synthesis, Characterization and 
Crystal Structure of [H3L][Cl]3·2H2O (L = 4,10-Dimethyl-1,4,7,10-Tetraazabicyclo [5.5.2] Tetradecane). Supramolecular Chemistry 1994, 3 (2), 141-146.

(47) Hubin, T. J.; McCormick, J. M.; Collinson, S. R.; Buchalova, M.; Perkins, C. M.; Alcock, N. W.; Kahol, P. K.; Raghunathan, A.; Busch, D. H. New Iron(II) and Manganese(II) Complexes of Two Ultra-Rigid, Cross-Bridged Tetraazamacrocycles for Catalysis and Biomimicry. Journal of the American Chemical Society 2000, 122 (11), 2512-2522.

(48) Bernier, N.; Costa, J.; Delgado, R.; Félix, V.; Royal, G.; Tripier, R. Trans-Methylpyridine Cyclen versus Cross-Bridged Trans-Methylpyridine Cyclen. Synthesis, Acid-Base and Metal Complexation Studies (Metal = Co2+, Cu2+, and Zn2+). Dalton Trans. 2011, 40 (17), 4514-4526.

(49) Gillet, R.; Roux, A.; Brandel, J.; Huclier-Markai, S.; Camerel, F.; Jeannin, O.; Nonat, A. M.; Charbonnière, L. J. A Bispidol Chelator with a Phosphonate Pendant Arm: Synthesis, Cu(II) Complexation, and 64Cu Labeling. Inorg. Chem. 2017, 56 (19), 11738-11752.

(50) Charpentier, C.; Salaam, J.; Nonat, A.; Carniato, F.; Jeannin, O.; Brandariz, I.; Esteban-Gomez, D.; Platas-Iglesias, C.; Charbonnière, L. J.; Botta, M. PH-Dependent Hydration Change in a Gd-Based MRI Contrast Agent with a Phosphonated Ligand. Chemistry - A European Journal 2020, 26 (24), 5407-5418.

(51) Ringbom, A. Les Complexes En Chimie Analytique; Ed. Dunod, France, 1967; p 369.

(52) Thom, V. J.; Hosken, G. D.; Hancock, R. D. Anomalous Metal Ion Size Selectivity of Tetraaza Macrocycles. Inorg. Chem. 1985, 24 (21), 3378-3381.

(53) Smith, R. M.; Martell, A. E.; Motekaitis, R. J. In Critical Stability Constants Database 46, version 5; NIST, Gaithersburg, MD, 1998.

(54) Motekaitis, R. J.; Rogers, B. E.; Reichert, D. E.; Martell, A. E.; Welch, M. J. Stability and Structure of Activated Macrocycles. Ligands with Biological Applications. Inorg. Chem. 1996, 35 (13), 38213827.

(55) Harris, W. R.; Carrano, C. J.; Raymond, K. N. Spectrophotometric Determination of the ProtonDependent Stability Constant of Ferric Enterobactin. J. Am. Chem. Soc. 1979, 101 (8), 2213-2214.

(56) Patel, R. N.; Shrivastava, R. P.; Singh, N.; Kumar, S.; Pandeya, K. B. Equilibrium Studies on MixedLigand Mixed-Metal Complexes of Copper(II), Nickel(II) and Zinc(II) with Glycylvaline and Imidazole. Indian Journal of Chemistry 2001, 40A (4), 361-367.

(57) Camus, N.; Bris, N. L.; Nuryyeva, S.; Chessé, M.; Esteban-Gómez, D.; Platas-Iglesias, C.; Tripier, R.; Elhabiri, M. Tuning the Copper(II) Coordination Properties of Cyclam by Subtle Chemical Modifications. Dalton Trans. 2017, 46 (34), 11479-11490.

(58) Sornosa Ten, A.; Humbert, N.; Verdejo, B.; Llinares, J. M.; Elhabiri, M.; Jezierska, J.; Soriano, C.; Kozlowski, H.; Albrecht-Gary, A.-M.; García-España, E. Cu2+ Coordination Properties of a 2-Pyridine Heptaamine Tripod: Characterization and Binding Mechanism. Inorg. Chem. 2009, 48 (18), 89858997.

(59) Abada, S.; Lecointre, A.; Elhabiri, M.; Charbonnière, L. J. Formation of Very Stable and Selective $\mathrm{Cu}(\mathrm{II})$ Complexes with a Non-Macrocyclic Ligand: Can Basicity Rival Pre-Organization? Dalton Trans. 2010, 39 (38), 9055-9062.

(60) Hathaway, B. J. The Correlation of the Electronic Properties and Stereochemistry of Mononuclear \{CuN4-6\} Chromophores. J. Chem. Soc., Dalton Trans. 1972, No. 12, 1196-1199.

(61) Wei, N.; Murthy, N. N.; Karlin, K. D. Chemistry of Pentacoordinate [LCuII-Cl]+ Complexes with Quinolyl Containing Tripodal Tetradentate Ligands L. Inorg. Chem. 1994, 33 (26), 6093-6100.

(62) Raymond, K. N.; Müller, G.; Matzanke, B. F. Complexation of Iron by Siderophores a Review of Their Solution and Structural Chemistry and Biological Function. In Topics in Current Chemistry; Springer: Berlin, Heidelberg, 1984; pp 49-102. 